\title{
Numerical Simulation of Impact Behavior of Ceramic Coatings Using Smoothed Particle Hydrodynamics Method
}

Jian Zhang ${ }^{1}$, Zhe Lu², Sugrim Sagar ${ }^{1}$, Hyunhee Choi ${ }^{3}$, Yeon-Gil Jung ${ }^{3}$, Heesung Park ${ }^{4}$, Dan Daehyun $\mathrm{Koo}^{5}$, Jing Zhang ${ }^{1 *}$

1. Department of Mechanical Engineering, Indiana University - Purdue University Indianapolis, USA

2. School of Materials and Metallurgical Engineering, University of Science and Technology Liaoning, China

3. Department of Materials Convergence and System Engineering, Changwon National University, Republic of Korea

4. School of Mechanical Engineering, Changwon National University, Republic of Korea

5. Department of Engineering Technology, Indiana University - Purdue University Indianapolis, USA

*Corresponding author: jz29@iupui.edu

This is the author's manuscript of the article published in final edited form as:

Zhang, J., Lu, Z., Sagar, S., Choi, H., Jung, Y.-G., Park, H., Koo, D. D., \& Zhang, J. (2020). Numerical Simulation of Impact Behavior of Ceramic Coatings Using Smoothed Particle Hydrodynamics Method. Journal of Engineering Materials and Technology, 143(2). https://doi.org/10.1115/1.4049021 


\section{Abstract}

In this work, the impact behavior of an alumina spherical particle on alumina coating is modeled using the smoothed particle hydrodynamics (SPH) method. The effects of impact angle $\left(0^{\circ}, 30^{\circ}\right.$, and $\left.60^{\circ}\right)$ and velocity $(100 \mathrm{~m} / \mathrm{s}, 200 \mathrm{~m} / \mathrm{s}$, and $300 \mathrm{~m} / \mathrm{s})$ on the morphology changes of the impact pit and impacting particle, and their associated stress and energy are investigated. The results show that the combination of impact angle of $0^{\circ}$ and velocity of $300 \mathrm{~m} / \mathrm{s}$ produces the highest penetration depth and largest stress and deformation in the coating layer, while the combination of $100 \mathrm{~m} / \mathrm{s} \&$ $60^{\circ}$ causes the minimum damage to the coating layer. This is because the penetration depth is determined by the vertical velocity component difference between the impacting particle and the coating layer, but irrelevant to the horizontal component. The total energy of the coating layer increases with the time, while the internal energy increases with the time after some peak values, which is due to energy transmission from the spherical particle to the coating layer and the stress shock waves. The energy transmission from impacting particle to coating layer increases with the increasing particle velocity, and decreases with the increasing inclined angle. The simulated impact pit morphology is qualitatively similar to the experimental observation. This work demonstrates that the SPH method is useful to analyze the impact behavior of ceramic coatings.

Keywords: Thermal barrier coating; Impact; Modeling; Smoothed particle hydrodynamics 


\section{Introduction}

Thermal barrier coating (TBC) is a multi-layer material system which usually consists of a top ceramic coating, typically $8 \mathrm{YSZ}$ due to its low thermal conductivity and good thermomechanical durability; and a metallic bond coat, e.g., NiCrAlY $[1,2]$. In practice, TBCs in gas turbines are susceptible to the damage caused by foreign particles. To protect TBC systems, an inlet particle separator is installed in most of the rotorcraft gas turbine engines to stop sand ingestion, but it is not completely efficient. Fine particles with a particle size less than $75 \mu \mathrm{m}$ cannot be filtrated [3]. Therefore, the top ceramic coat in TBCs has shown vulnerability to intake flows that contain sand, dust, and/or fly ash, which adhere and react at high temperatures. It may cause premature failure in the components through both impingement and combined mechanical-thermal-chemical attack $[4,5]$.

There are several studies regarding $\mathrm{TBC}$ failure process due to foreign particle impact or the erosion process. The failure process of $\mathrm{Al}_{2} \mathrm{O}_{3} / \mathrm{NiCrAlY} / \mathrm{SUS} 304$ atmospheric plasma spray coating was studied. It was found that the shear mode of microfracture occurred toward the center from the edges of the specimen [6]. In addition, turbine blade surface deterioration caused by erosion was investigated. The results indicated that both erosion and surface roughness increased with the impact angle and particle size [7]. Additionally, the optimization of blade section shape subject to particle erosion in an aerodynamic standpoint was investigated. It concluded that the erosive damage to the surface was represented by sand grains colliding with the blade leading edge [8]. In terms of modeling, simulation of ballistic impact on ceramic material was conducted with Johnson Holmquist ceramic model (JHC). Plate impact simulations on silicon carbide were performed and compared to experimental loading and unloading curves [9]. Also, the sand corrosion behavior for ceramic coating was studied using a computational fluid dynamics model. The numerical results 
for the eroded surface geometry and the performance deterioration showed the same tendency as the experimental data [10]. Also, non-ordinary state-based peridynamics was used to understand the fracture in brittle ice due to particle impact. However, the effects of velocity and impact angle on the fracture were not included in the study [11]. High-speed impacts and penetration processes usually cause large deformations. Traditional grid-based numerical methods such as finite element method (FEM) is generally difficult to simulate large deformation due to severe mesh distortions. In comparison, the SPH method has shown to be very useful to model the high-speed particles to accommodate their extremely large deformation, which is important for brittle fracture of ceramic materials [12]. As a mesh-free, Lagrangian particle method, the SPH method can be used to handle large distortions. It is particularly suitable to study some fast-transient dynamics problems and the severe deformation of the particle $[14,15]$. The phenomena of impact onto ceramic/aluminum composites were modeled using the smoothed particle hydrodynamics (SPH) method. Results indicated that, with the increasing initial velocity and ceramic thickness, and decreasing support layer thickness, the penetration area was increased. However, the work used a projectile meshed with finite element [13]. In summary, despite of the above-mentioned efforts, a detailed study of the impact behavior of particle on a ceramic coating is still lacking.

In this study, the existing SPH methods implemented in LS-DYNA are used to simulate the impact behavior of an alumina particle on an alumina ceramic coating. The structure of the paper is as follows. Section 2 presents the model description. The general formulation of the SPH methods and the model details in the study are provided. The focus is to understand how the impacting particle's inclined angle and velocity affect the morphology changes of the impact pit and impacting particle, and their associated stress and energy. Section 3 gives the results and discussion. 
Section 4 presents the simulation results compared against experimental observation. Finally, Section 5 summarizes the conclusion.

The simulation results help deeply understanding of the impact process which is nearly impossible completed in the lab. In addition, it can help to improve the manufacturing process of the thermal barrier coating. Also, the removing and repair process of damaged TBCs will be studied based on these simulation results.

\section{Model description}

\subsection{Smoothed Particle Hydrodynamics (SPH) method}

In SPH models, the value of a function $f$ at a position $r_{i}$ can be calculated by the following particle summation [14]:

$$
\begin{aligned}
& f\left(r_{i}\right)=\sum_{j=1}^{N} \frac{m_{j}}{\rho_{j}} f\left(r_{j}\right) W\left(r_{i}-r_{j}, h\right) \\
& W\left(r_{i}-r_{j}, h\right)=\frac{1}{h} \Theta\left[\frac{r_{i}-r_{j}}{h(r, y)}\right]
\end{aligned}
$$

where $m$ and $\rho$ are the mass and density of a particle, respectively. $W$ is a kernel function, which is the cubic B-spline function in LS-DYNA, where $h$ is a smoothing length of the kernel to control the size of the summation domain. $W\left(r_{i}-r_{j}, h\right) \rightarrow \delta$ when $h \rightarrow 0$, where $\delta$ is the Dirac function [14]. The initial number of neighbors per particle in the model is set to 150 . The number can be adjusted in the process.

In general, the compact support is defined by the smoothing length $h$ and a scale factor $\kappa$ that determines the spread of the specified smoothing function. So the compact support means

$$
W\left(r_{i}-r_{j}, h\right)=0 \quad \text { when }\left|r_{i}-r_{j}\right|>0
$$


An equation of state (EOS) is required for materials that undergo significant deformation, such as large plastic deformation or a compressible fluid. The Cauchy stress tensor can be separated into a hydrostatic stress tensor and a deviatoric stress tensor. The deviatoric stress is calculated by the material model constitutive law. The pressure term must then come from an EOS. The EOS provides a relationship between pressure and volume. Depending on the compressibility of the material, different types of EOS's are possible [15]. A commonly used EOS is the Mie-Grüneisen equation of state as follows [16,17]:

$$
p=\frac{\rho_{0} C^{2} \mu\left[1+(1-\gamma / 2) \mu-(\alpha / 2) \mu^{2}\right]}{\left[1-\left(S_{1}-1\right) \mu-S_{2} \mu^{2} /(\mu+1)-S_{3} \mu^{3} /(1+\mu)\right]^{2}}+(\gamma+\alpha \mu) E_{0}
$$

where $p$ is pressure; $S_{1}, S_{2}, S_{3}$ are the coefficients of the slope of the $U_{s}-U_{p}$ curve, where $U_{s}$ and $U_{p}$ are shock wave velocity and particle velocity, respectively; $\gamma$ is the Grüneisen factor; $C$ is the Hugoniots intercept of the $U_{s}-U_{p}$ curve [17]; $E_{0}$ is internal energy; $\alpha$ is volume correction factor; and $\mu=\rho / \rho_{0}-1$ is compression factor, where $\rho / \rho_{0}$ is the ratio of current density to initial density.

The Johnson-Holmquist Plasticity Damage Model was first proposed to describe the response of brittle materials for large deformation in 1992 and proved to be useful for modeling ceramics, glass and other brittle materials. The equivalent stress for a ceramic-type material is given in terms of the damage parameter $\mathrm{D}$ by

$$
\sigma^{*}=\sigma_{i}^{*}-D\left(\sigma_{i}^{*}-\sigma_{\mathrm{f}}^{*}\right)
$$

where

$$
\sigma_{i}^{*}=a\left(p^{*}+t^{*}\right) n(1+c \ln \dot{\varepsilon} *)
$$

represents the intact, undamaged behavior. The superscript, '*', indicates a normalized quantity. $a$ is the intact normalized strength parameter, $c$ is the strength parameter for strain rate dependence, $\dot{\varepsilon} *$ is the normalized plastic strain rate, and, 


$$
\begin{aligned}
t^{*} & =\frac{T}{P H E L} \\
p^{*} & =\frac{\mathrm{p}}{\text { PHEL }}
\end{aligned}
$$

where $T$ is the maximum tensile pressure strength, PHEL is the pressure component at the Hugoniot elastic limit, and $p$ is the pressure.

$$
\mathrm{D}=\sum \frac{\Delta \varepsilon^{\mathrm{p}}}{\varepsilon_{f}^{\mathrm{p}}}
$$

represents the accumulated damage based upon the increase in plastic strain per computational cycle and the plastic strain to fracture

$$
\varepsilon_{f}^{\mathrm{p}}=d_{1}\left(p^{*}+t^{*}\right)^{d^{2}}
$$

and

$$
\sigma_{\mathrm{f}}^{*}=b(p *)^{m}(1+c \ln \dot{\varepsilon} *) \leqslant \mathrm{SFMAX}
$$

represents the damaged behavior. The parameter $\mathrm{d}_{1}$ controls the rate at which damage accumulates. In undamaged material, the hydrostatic pressure is given by

$$
P=k_{1} \mu+k_{2} \mu^{2}+k_{3} \mu^{3}
$$

in compression and

$$
P=k_{1} \mu
$$

in tension where $\mu=\rho / \rho_{0}-1[18]$

\subsection{Numerical model details}

The SPH model set up is shown in Fig.1. A spherical alumina particle with a diameter of $60 \mu \mathrm{m}$ is used as the impacting particle, which is meshed with the SPH particles. The layered alumina ceramic coating is modeled as a block with the dimension of $500 \times 500 \times 125 \mu^{3}$. The top layer is meshed with SPH with a thickness of $25 \mu \mathrm{m}$, and the bottom layer is meshed by finite element with a thickness of $100 \mu \mathrm{m}$. Connect nodes are used to bond the top and bottom layers. The bottom of bottom layer is fixed. The layered structure allows to efficiently capture the deformation process 
during impact and reduce the computational costs. Based on the mesh convergence analysis, the total number of particles for the SPH coating layer is 200,000 . The total number of particles for the SPH sphere is 14,328 . The total number of nodes for the FEM coating layer is 10,571 . The used mesh density follows Ref. [19].

The spherical particle and the SPH coating layer are made of the same material. The density of ceramic coating is $3420 \mathrm{~kg} / \mathrm{m}^{3}$, the shear modulus is $108 \mathrm{GPa}$ and the Poisson's ratio is 0.22 [16].

The parameters used in the SPH Mie-Grüneisen equation of state in Eq. 4 are shown in Table 1 [16], which assumes alumina. The parameters of *MAT_JOHSNON_HOLMQUIST_CERAMIC (JH-2) used in the FEM layer are shown in Table 2 [20].

In order to couple the FEM bottom layer and SPH top layer, *AUTOMATIC_NODES_TO_SURFACE is selected to calculate the forces exchanging between FE elements and SPH particles near the coupling interface. Contact nodes to surface are used between the top SPH layer and bottom FEM layer. As a Lagrangian method, the interaction between SPH particles and FEM elements can be easily handled by a normal node to surface contact in LS-DYNA [21].

To evaluate the effect of impact angle and velocity on the impact behavior of the coatings, different impact angles and velocities are combined using a design matrix approach, as shown in Table 3. The impact velocity values are 100,200 , and $300 \mathrm{~m} / \mathrm{s}$, and the impact angles are $0^{\circ}, 30^{\circ}$, and $60^{\circ}$. The impact angle is defined between the impacting velocity and the normal of the top coating surface. The corresponding velocity components, $\mathrm{Vx}$ and $\mathrm{Vz}$, are also provided in the Table 3. 
Moreover, in order to understand the role of horizontal velocity component Vx on the penetration depth, the vertical velocity component $\mathrm{Vz}$ is fixed at $259.8 \mathrm{~m} / \mathrm{s}$. The $\mathrm{Vx}$ values are then varied as 0,150 , and $259.8 \mathrm{~m} / \mathrm{s}$, which corresponds to impact angle of $0^{\circ}, 30^{\circ}$, and $60^{\circ}$.

To ensure stability and convergence of the The energy absorbed by the coating decreases simulations, the Moving Least-Squares (MLS) approximation and an improved nodal integration scheme in LS-DYNA are used, which has shown to be much more stable in tension[22]. Additionally, option *CONTROL_BULK_VISCOSITY is enabled in the model since it slightly dampens out large oscillations at little numerical cost and with little energy cost [15].

\section{Results and discussion}

\subsection{Damage of the ceramic coating layer}

The side views of the impact process with different impact angles and velocities are summarized

in Fig.2. It is clear that the penetration effect with the same angle increases with the increasing velocity. At the same time, the penetration effects decrease with the increasing impact angle at the same velocity. The case of velocity $300 \mathrm{~m} / \mathrm{s}$ and impact angle $0^{\circ}$ (Fig. $2 \mathrm{~g}$ ) has the maximum penetration effect, while the case of velocity $100 \mathrm{~m} / \mathrm{s}$ and impact angle $60^{\circ}$ (Fig. 2c) has the minimum penetration.

The extent of particle penetration and coating particle spattering increase with the vertical velocity component $V z$, where the impact energy is proportional to $1 / 2 \mathrm{~m} V_{z}^{2}$. Also shown in Fig. 2, the spattered particles on the coating layer have a symmetric pattern along the impact surface when the impact angle is $0^{\circ}$. However, the spreading of particles increases with the increasing impact angle. 
Fig.3 shows the von Mises stress and impact penetration profiles of the coatings [23]. The von Mises stresses increase with the increasing velocity at the same impact angle. The distributions of the stress at the same angle have the same characteristics. The stress distributes are in a ring shape with an impact angle $0^{\circ}$. The difference of stress distribution is caused by the horizontal velocity component $\mathrm{Vx}$, which is most obvious in the case of combination of $300 \mathrm{~m} / \mathrm{s} \& 60^{\circ}$.

On the other hand, it is clear that the penetration depth and area increase with the increasing velocity at the same angle. Also, the penetration depth and area decrease with the increasing impact angle at the same velocity. The case of velocity $300 \mathrm{~m} / \mathrm{s}$ and impact angle $0^{\circ}$ has the maximum penetration depth. The case of velocity $100 \mathrm{~m} / \mathrm{s}$ and impact angle $60^{\circ}$ has the minimum penetration depth and area.

The coating's energy evolutions at different angles and velocities are shown from Figs. 4 to 7. Fig. 4 shows the total energy and internal energy evolutions at different combination of angles and velocities, respectively. In LS-DYNA, total energy is the sum of internal energy, kinetic energy, contact (sliding) energy, hourglass energy, system damping energy and rigid wall energy [18, 24]. The results show that the total energy increases linearly with time.

Fig. 5 shows the internal energy evolutions at different combination of angles and velocities. Internal energy is computed based on the six components of stress and strain (tensorial values). The calculation is done incrementally for each particle as follows: (IE) new $=($ IE) old + sum over all six directions of (stress $\times$ incremental strain $\times$ volume). The internal energies of all the elements is summed to give the total internal energy. $[18,24]$. The results show that the internal energy increases with time. 
Additionally, Fig.5 shows that the internal energy has a few peaks before it starts increasing gradually after a period of impact. This phenomenon is most evident with the combination of 100 $\mathrm{m} / \mathrm{s} \& 0^{\circ}, 30^{\circ}$, and $60^{\circ}$. Taking $100 \mathrm{~m} / \mathrm{s} \& 0^{\circ}$ for example, Fig. 5 (a) shows that the internal energy has the maximum value at the time $1 \mathrm{~ms}$ and the minimum value nearly $0 \mathrm{~J}$ at $4 \mathrm{~ms}$. It is due to the conversion of kinetic energy of the spherical particle to internal energy immediately after the impact. As a result, the internal energy reaches the maximum value at the same time. The internal energy at the peak value is mainly stored at the impact point. As the impact process continues, the stress shock waves transmit through the coating. Then the internal energy decreases sharply. After $4 \mathrm{~ms}$, the internal energy increases linearly as the impact area increases and the transition of stress wave becomes stable.

The total energy values of the coating at the end of impact are shown in Fig.6. The total energy of coating layer with the same velocity decreases with increasing impact angle. The highest velocity $300 \mathrm{~m} / \mathrm{s}$ has the highest total energy and internal energy. The energy absorbed by the coating decreases with the increase of the angle. It is caused by the existence of the horizontal velocity component $\mathrm{Vx}$. The initial energy converted to the internal energy or doing work becomes less.

The internal energy values of the coating at different impact angles at the end of impact are shown in Fig.7. It shows the same regular pattern with the total energy, decreasing with the increasing angle. This is because more initial energy is absorbed by the impact parts to deformation when the impact effect is higher.

To understand the effect of the vertical velocity component on the internal energy, the relation between the internal energy and the square of the vertical velocity is plotted in Fig. 8 . The figure 
shows that there is a linear correlation between the two quantities, suggesting the internal energy change of the coatings is controlled by the particle's kinetic energy.

To understand the role of horizontal velocity component $\mathrm{Vx}$ on the impact behavior, $\mathrm{Vx}$ is varied to 0,150 , and $259.8 \mathrm{~m} / \mathrm{s}$, while keeping the same vertical velocity component $\mathrm{Vz}$ of $259.8 \mathrm{~m} / \mathrm{s}$. The combinations of the velocity components correspond to impact angle of $0^{\circ}, 30^{\circ}$ and $45^{\circ}$, respectively.

Fig.9 shows sectional views of the von Mises stress and impact penetration profiles of the coatings. The impact spherical particle comes from the right side of the figure. As the impact angle increases, high stresses concentrate on the left side of the impact pit, due to the increased horizontal velocity component.

Figure 10 shows that the penetration depth is mainly controlled by the vertical velocity component, not the horizontal one, irrespective of the impact angles. A good linear relation $\left(\mathrm{R}^{2}=0.9579\right)$ is obtained between the vertical velocity component and the penetration depth.

To better understand the interface between the SPH and FEM layer, the von Mises stresses and impact penetration profiles of the FEM layer are plotted in Fig. 11, for the combination $300 \mathrm{~m} / \mathrm{s} \&$ $0^{\circ}$ case. The distribution of stress is mainly concentrated on the impacted area. The maximum stress does not locate at the interface, but rather beneath it. It is consistent with the distribution of SPH layer. In addition, the domain of stress distribution is symmetrical in both vertical and horizontal direction because of no horizontal velocity existing. On the other hand, the magnitude of stress in the FEM layer is much higher than that in the SPH layer. It could be caused by the different formulations between the FEM and SPH layers. 
The von Mises stress evolution of the coating layer at different times of the combination $100 \mathrm{~m} / \mathrm{s}$ $\& 0^{\circ}$ is shown in Fig.12, which is consistent with the internal energy changes shown in Fig. 5. At $1 \mathrm{~ms}$, the von Mises stress is high and nearly no penetration occurs. At $4 \mathrm{~ms}$, the stress decreases sharply, and the stress wave propagates around. A ring-shaped stress pattern is formed. As the impact process proceeds, the coating penetration occurs because the decreased energy is converted to coating deformation. As shown in Fig.12 (c), the particle protrusion at $50 \mathrm{~ms}$ is most evident.

\subsection{Deformation of spherical impacting particle}

Fig.13 and Fig.14 show the spherical particle deformation after the impact for different impact velocities and angles, respectively. It is clear that the deformation of the spherical particle increases with the increasing of impact velocity, and decreases with the increasing of impact angle. The increasing deformation of spherical particle with the same impact angle is consistent with the increasing depth of the impact pit shown in Fig.3 (a), (d) and (g). The damage of the spherical particle and the ceramic layer is increasing with the increasing impact velocity.

During the impact, the kinetic energy of the spherical particle is transmitted to the coating layer, and it increases with the increasing velocity. This is confirmed by the increasing total and internal energies of the coating layer as shown in Fig.4 and Fig.5, and the decreased kinetic energy of the spherical particle as shown in Fig.15, Fig.16 and Fig.17. Fig.16 shows the spherical particle's

maximum, minimum and range kinetic energy values at different impact velocities. The kinetic energy transmitted from the spherical particle to coating layer is related to the vertical velocity difference between the particle and the coating layer. In addition, the energy transmitted from the 
spherical particle to the coating decreases with the increasing of the impact angle as shown in Fig.16, suggesting the vertical velocity component is the dominant factor. It is also consistent with the particle deformation shown in Fig.14.

\section{Experimental comparison}

To compare with the experimental data, a scanning electron microscope (SEM) image of the sphere compaction on an electron beam physical vapor deposition (EB-PVD) yttria-stabilized zirconia (YSZ) ceramic coating [25] is shown in Fig. 18. It is evident that the impact pit observed in the experiment has a similar pattern as the simulated one shown in Fig.8a. Thus, a qualitative agreement is achieved between the SPH model and experiment. It is noted that more quantitative comparisons would be needed, which would be included in the future work.

\section{Conclusions and future work}

In this work, an SPH based model to simulate the impact of spherical ceramic particle on ceramic coatings is developed. The detailed conclusions are summarized as follows.

(1) Compared to previous studies, both the spherical particle and the coating are meshed with $\mathrm{SPH}$, which allows us to study their large deformations during the impact.

(2) Increasing impact velocity or reducing impact angle increases the penetration depth and area. The penetration depth is determined by the vertical velocity component difference between the particle and the coating layer. However, it is not related to the horizontal velocity component. 
(3) During the impact process, the coating's total energy increases gradually while the internal energy increases with the time after some peak values, which is due to the kinetic energy of the spherical particle converted to internal energy immediately after the impact, and the stress shock wave transmission in the coating layer.

(4) At the end of impact, the coating's total energy increases with the increasing impact velocity but deceases with increasing impact angle. It is consistent with the deformations of the coating layer and spherical particle.

(5) The penetration depth is mainly controlled by the vertical velocity component, in a linear relation.

(6) The combination of $300 \mathrm{~m} / \mathrm{s} \& 0^{\circ}$ has the maximum penetration to the coating layer and the combination of $100 \mathrm{~m} / \mathrm{s} \& 60^{\circ}$ has the minimum penetration. It is due to the fact that penetration is dominated by the particle's vertical velocity component.

(7) The simulated pit morphology is qualitatively similar to the experimental observation. This work demonstrates that the SPH method is useful for analyzing the impact effect in the ceramic coating.

In terms of future work, a more precise and quantitative validation experiment is recommended. This allows the model to be more accurately calibrated and can be used for industrial applications.

\section{Acknowledgment}

This work is partially supported by "Human Resources Program in Energy Technology (No. 20194030202450) and (No. 20181110100310)" of the Korea Institute of Energy Technology

Evaluation and Planning (KETEP). ZL acknowledges the financial support provided by the National Natural Science Foundation of China (No. 51702145). 


\section{Conflict of interest statement}

On behalf of all authors, the corresponding author states that there is no conflict of interest. 


\section{References}

1. Zhang, J. and Y.-G. Jung, Advanced ceramic and metallic coating and thin film materials for energy and environmental applications. 2018: Springer.

2. Zhang, J., Guo, X., Jung, Y. G., Li, L., \& Knapp, J., Lanthanum zirconate based thermal barrier coatings: A review. Surface and Coatings Technology, 2017. 323: p. 18-29.

3. Chawla, N. and K. Chawla, Microstructure-based modeling of the deformation behavior of particle reinforced metal matrix composites. Journal of Materials Science, 2006. 41(3): p. 913925.

4. Murugan, M., Ghoshal, A., Walock, M. J., Barnett, B. D., Pepi, M. S., \& Kerner, K. A., Sand particle-Induced deterioration of thermal barrier coatings on gas turbine blades. Advances in aircraft and spacecraft science, 2017. 4(1): p. 37-52.

5. Liu, X., Tang, P., Geng, Q., \& Wang, X., Effect of Abrasive Concentration on Impact Performance of Abrasive Water Jet Crushing Concrete. Shock and Vibration, 2019. 2019.

6. Nishinoiri, S., M. Enoki, and K. Tomita, Evaluation of microfracture mode in ceramic coating during thermal cycle test using laser AE technique. Materials Transactions, 2004. 45(1): p. $92-101$.

7. Hamed, A. A., Tabakoff, W., Rivir, R. B., Das, K., \& Arora, P., Turbine blade surface deterioration by erosion. Journal of turbomachinery, 2005. 127(3): p. 445-452.

8. Fiore, G. and M.S. Selig. Optimization of wind turbine airfoils subject to particle erosion. in 33rd AIAA Applied Aerodynamics Conference. 2015. 
9. Lamberts, A. P. T. M. J., Geers, M. G. D., van Dommelen, J. A. W., de Lange, H. C., Huizinga, A. T. M. J. M., \& BV, P. A., Numerical simulation of ballistic impacts on ceramic material. Eindhoven University of Technology, 2007.

10. Suzuki, M. and M. Yamamoto, Numerical simulation of sand erosion phenomena in a single-stage axial compressor. Journal of Fluid Science and Technology, 2011. 6(1): p. 98-113.

11. Song, Y., Yan, J., Li, S., \& Kang, Z., Peridynamic Modeling and Simulation of Ice Craters By Impact. CMES-COMPUTER MODELING IN ENGINEERING \& SCIENCES, 2019. 121(2): p. $465-492$.

12. Guo, L., S. Deng, and X. Yang, Numerical simulation of abrasive water jet cutting chemical pipeline based on SPH coupled FEM. Chemical Engineering Transactions, 2016. 51: p. $73-78$.

13. Hedayati, E. and M. Vahedi, Numerical investigation of penetration in ceramic/aluminum targets using smoothed particle hydrodynamics method and presenting a modified analytical model. Computer Modeling in Engineering \& Sciences, 2017. 113(3): p. 295-323.

14. Ray, M., X. Yang, and S.-C. Kong, Simulation of Drop Impact on a Hot Wall using SPH Method with Peng-Robinson Equation of State. arXiv preprint arXiv:1707.03850, 2017.

15. Chou, I. M., Blank, J. G., Goncharov, A. F., Mao, H. K., \& Hemley, R. J., In Situ Observations of a High-Pressure Phase of $\mathrm{H}_{2} \mathrm{O}$ Ice. SCIENCE, 1998. 281: p. 809-812.

16. Vahedi, K. and N. Khazraiyan. Numerical modeling of ballistic penetration of long rods into ceramic/metal armors. in 8th International LS-DYNA Users Conference. 2004.

17. Johnson, J., General features of Hugoniots. Report LANL LA, 1996. 13137. 
18. Hallquist, J.O., LS-DYNA® keyword user's manual: volumes I, II, and III LSDYNA R7. 1. Livermore Software Technology Corporation, Livermore (LSTC), Livermore, California, 2014. 1265.

19. Barsotti, M. Comparison of FEM and SPH for modeling a crushable foam aircraft arrestor bed. in 11th International LS-DYNA Users Conference (accessed 10/23/2020, https://www.dynalook.com/conferences/international-conf-2010/Aerospace-2-3.pdf). 2010.

20. Cronin, D. S., Bui, K., Kaufmann, C., McIntosh, G., Berstad, T., \& Cronin, D., Implementation and validation of the Johnson-Holmquist ceramic material model in LS-Dyna. in Proc. 4th Eur. LS-DYNA Users Conf. 2003.

21. $\mathrm{Xu}, \mathrm{J}$. and J. Wang, Node to node contacts for SPH applied to multiple fluids with large density ratio, in Proceedings of the 9th European LS-DYNA users conference, Manchester, U.K. 2013.

22. Yreux, E., MLS-based SPH in LS-DYNA ${ }^{\circledR}$ for Increased Accuracy and Tensile Stability, in 15th International LS-DYNA Users Conference. 2018.

23. Ho and Philip, LS-PRE/POST v1.0. Livermore 2002, Livermore Software Technology Corporation, .

24. Hallquist, J.O., LS-DYNA theory manual. Livermore software Technology corporation, 2006. 3: p. 25-31.

25. Wellman, R.G. and J.R. Nicholls, A review of the erosion of thermal barrier coatings. Journal of Physics D: Applied Physics, 2007. 40(16): p. R293-R305. 


\section{List of Figure Captions}

Fig.1. SPH model of a spherical alumina particle impacting on an alumina coating

Fig.2. Side view of the impact with different velocities and impact angles (a) $100 \mathrm{~m} / \mathrm{s} \& 0^{\circ}$, (b) $100 \mathrm{~m} / \mathrm{s} \& 30^{\circ}$, (c) $100 \mathrm{~m} / \mathrm{s} \& 60^{\circ}$, (d) $200 \mathrm{~m} / \mathrm{s} \& 0^{\circ}$, (e) $200 \mathrm{~m} / \mathrm{s} \& 30^{\circ}$, (f) $200 \mathrm{~m} / \mathrm{s} \& 60^{\circ}$, , g) $300 \mathrm{~m} / \mathrm{s} \& 0^{\circ}$, (h) $300 \mathrm{~m} / \mathrm{s} \& 30^{\circ}$, and (i) $300 \mathrm{~m} / \mathrm{s} \& 60^{\circ}$

Fig.3. von Mises stress distributions in the coating layers at the end of impact: (a) $100 \mathrm{~m} / \mathrm{s} \& 0^{\circ}$, (b) $100 \mathrm{~m} / \mathrm{s} \& 30^{\circ}$, (c) $100 \mathrm{~m} / \mathrm{s} \& 60^{\circ}$, (d) $200 \mathrm{~m} / \mathrm{s} \& 0^{\circ}$, (e) $200 \mathrm{~m} / \mathrm{s} \& 30^{\circ}$, (f) $200 \mathrm{~m} / \mathrm{s} \& 60^{\circ}$, (g) $300 \mathrm{~m} / \mathrm{s} \& 0^{\circ}$, (h) $300 \mathrm{~m} / \mathrm{s} \& 30^{\circ}$, and (i) $300 \mathrm{~m} / \mathrm{s} \& 60^{\circ}$

Fig.4. Total energy evolutions of the coating layer at different impact angles and velocities. (a) $100 \mathrm{~m} / \mathrm{s} \& 0^{\circ}, 30^{\circ}, 60^{\circ}$; (b) $200 \mathrm{~m} / \mathrm{s} \& 0^{\circ}, 30^{\circ}, 60^{\circ} ;$ (c) $300 \mathrm{~m} / \mathrm{s} \& 0^{\circ}, 30^{\circ}, 60^{\circ}$

Fig.5. Internal energy evolution of the coating layer at different impact angles and velocities. (a) $100 \mathrm{~m} / \mathrm{s} \& 0^{\circ}, 30^{\circ}, 60^{\circ}$; (b) $200 \mathrm{~m} / \mathrm{s} \& 0^{\circ}, 30^{\circ}, 60^{\circ} ;$ (c) $300 \mathrm{~m} / \mathrm{s} \& 0^{\circ}, 30^{\circ}, 60^{\circ}$

Fig.6. The final total energy values of SPH coating layer at different impact angles and velocities at the end of impact at $100 \mathrm{~ms}$

Fig.7. The final internal energy values of SPH coating layer at different impact angles and velocities at the end of impact at $100 \mathrm{~ms}$

Fig. 8. Internal energy of the coating as a function of square of the vertical velocity component of the particle

Fig.9. von Mises stress and penetration behavior of the coating layers after the impact: Vx and Vz are (a) $\mathrm{Vx}=0 \mathrm{~m} / \mathrm{s} \& 259.8 \mathrm{~m} / \mathrm{s}$, (b) $150 \mathrm{~m} / \mathrm{s} \& 259.8 \mathrm{~m} / \mathrm{s}$, and (c) $259.8 \mathrm{~m} / \mathrm{s} \& 259.8 \mathrm{~m} / \mathrm{s}$

Fig.10. Coating penetration depth as a function of particle's vertical velocity component 
Fig.11. von Mises stress distribution in the FEM layer of the combination $300 \mathrm{~m} / \mathrm{s} \& 0^{\circ}$

Fig.12. von Mises stress distribution evolutions of SPH coating layer at the combination $100 \mathrm{~m} / \mathrm{s}$ $\& 0^{\circ}$ at different times. (a) $1 \mathrm{~ms}$; (b) $4 \mathrm{~ms}$; and (c) $50 \mathrm{~ms}$

Fig.13. The spherical particle deformation after the impact: (a) $300 \mathrm{~m} / \mathrm{s} \& 0^{\circ}$, (b) $200 \mathrm{~m} / \mathrm{s} \& 0^{\circ}$, (c) $100 \mathrm{~m} / \mathrm{s} \& 0^{\circ}$

Fig. 14. The spherical particle deformation after the impact: (a) $300 \mathrm{~m} / \mathrm{s} \& 0^{\circ}$, (b) $300 \mathrm{~m} / \mathrm{s} \& 30^{\circ}$, (c) $300 \mathrm{~m} / \mathrm{s} \& 60^{\circ}$

Fig.15. Kinetic energy evolutions of spherical particle at different impact velocities

Fig.16. Kinetic energy evolution of spherical particle at different impact angles

Fig.17. The spherical particle's maximum, minimum and range of kinetic energy values at different impact velocities: $300 \mathrm{~m} / \mathrm{s} \& 0^{\circ}, 200 \mathrm{~m} / \mathrm{s} \& 0^{\circ}$ and $100 \mathrm{~m} / \mathrm{s} \& 0^{\circ}$

Fig.18. Cross sectional view of the experimental impact pit of YSZ ceramic coating [25] 


\section{List of Table Headings}

Table 1. Parameters used in the Mie-Grüneisen equation of state for the SPH ceramic layer [16]

Table 2. JH-2 parameters of finite element ceramic layer [20]

Table 3. Design matrix of impact velocities $\mathrm{Vx}$ and $\mathrm{Vz}$ components $(\mathrm{m} / \mathrm{s})$ at three impact angles,

$0^{\circ}, 30^{\circ}$, and $60^{\circ}$ 
Table 1. Parameters used in the Mie-Grüneisen equation of state for the SPH ceramic layer [16]

\begin{tabular}{|c|c|c|c|c|}
\hline $\mathrm{C}(\mathrm{m} / \mathrm{s})$ & $\mathrm{S}_{1}$ & $\mathrm{~S}_{2}$ & $\mathrm{~S}_{3}$ & $\gamma$ \\
\hline 9003 & -3.06 & 2.350 & -0.383 & 1 \\
\hline
\end{tabular}


Table 2. JH-2 parameters of finite element ceramic layer [20]

\begin{tabular}{|c|c|}
\hline Parameters & Value \\
\hline $\mathrm{A}$ & 0.93 \\
\hline $\mathrm{B}$ & 0.31 \\
\hline $\mathrm{C}$ & 0 \\
\hline $\mathrm{M}$ & 0.6 \\
\hline $\mathrm{N}$ & 0.6 \\
\hline $\mathrm{HEL}(\mathrm{GPa})$ & 2.79 \\
\hline $\mathrm{PHEL}$ & 1.46 \\
\hline $\mathrm{D} 1$ & 0.005 \\
\hline $\mathrm{D} 2$ & 1 \\
\hline $\mathrm{K}_{1}(\mathrm{GPa})$ & 130.95 \\
\hline $\mathrm{K}_{2}(\mathrm{GPa})$ & 0 \\
\hline $\mathrm{K}_{3}(\mathrm{GPa})$ & 0 \\
\hline
\end{tabular}


Table 3. Design matrix of impact velocities Vx and Vz components $(\mathrm{m} / \mathrm{s})$ at three impact angles,

$$
0^{\circ}, 30^{\circ} \text {, and } 60^{\circ}
$$

\begin{tabular}{|c|c|c|c|c|c|}
\hline \multicolumn{2}{|c|}{$0^{\circ}$} & \multicolumn{2}{c|}{$30^{\circ}$} & \multicolumn{2}{c|}{$60^{\circ}$} \\
\hline $\mathrm{Vx}$ & $\mathrm{Vz}$ & $\mathrm{Vx}$ & $\mathrm{Vz}$ & $\mathrm{Vx}$ & $\mathrm{Vz}$ \\
\hline 0 & 100 & 50 & 86.6 & 86.6 & 50 \\
\hline 0 & 200 & 100 & 173.2 & 173.2 & 100 \\
\hline 0 & 300 & 150 & 259.8 & 259.8 & 150 \\
\hline
\end{tabular}




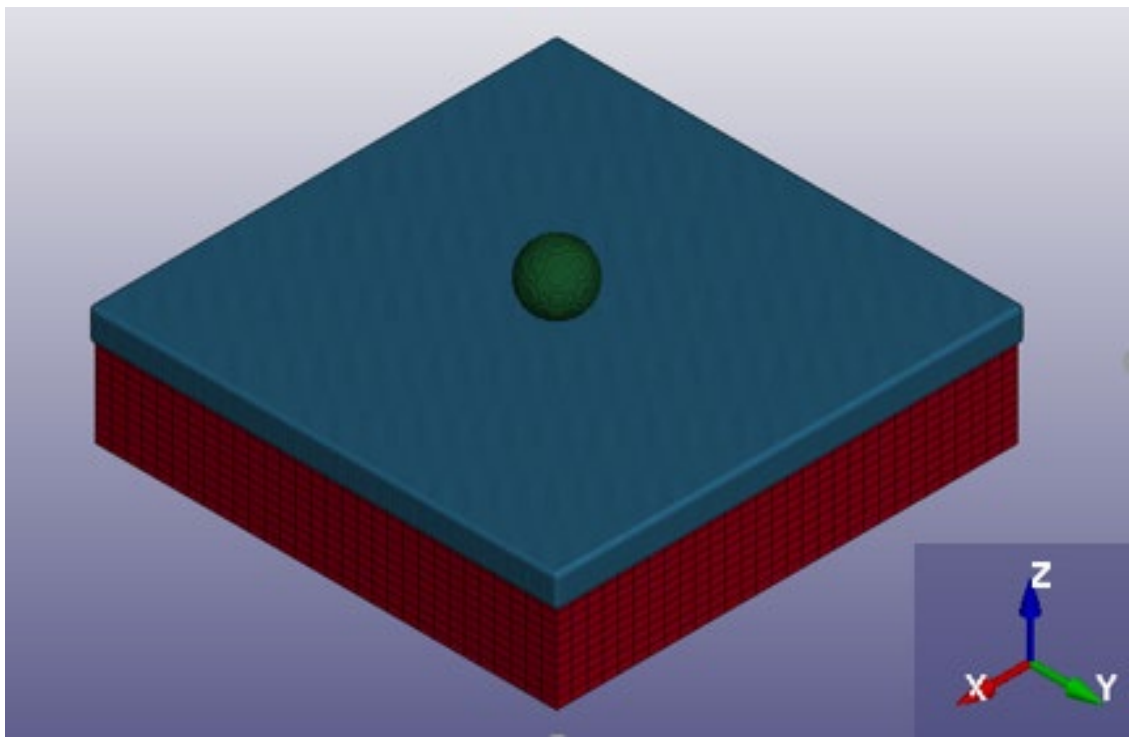

Fig.1. SPH model of a spherical alumina particle impacting on an alumina coating 


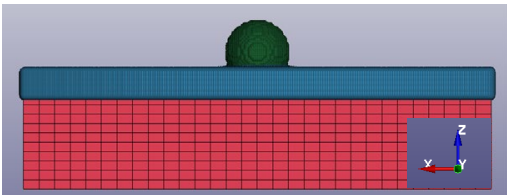

(a)

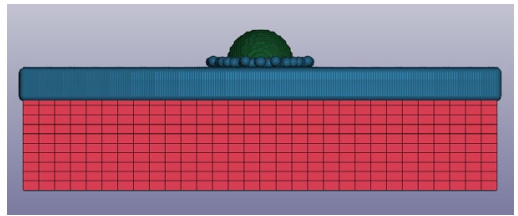

(d)

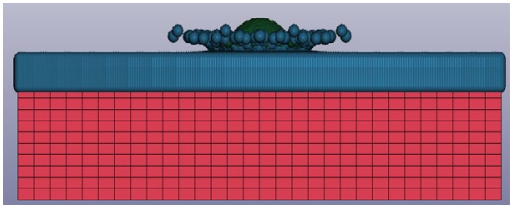

(g)

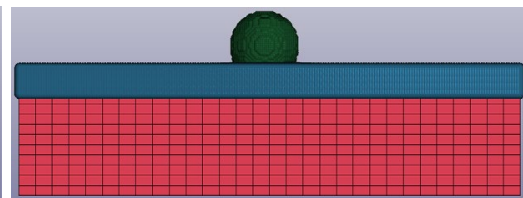

(b)

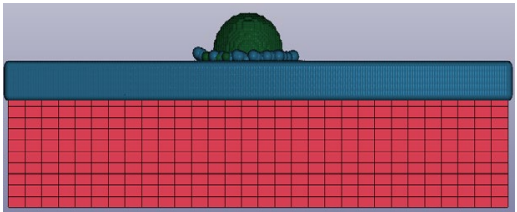

(e)

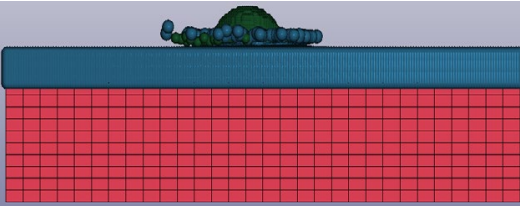

(h)

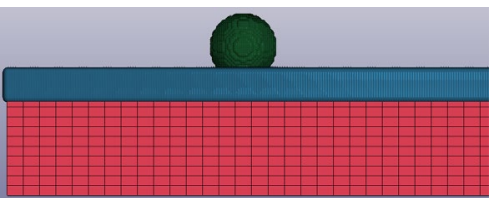

(c)

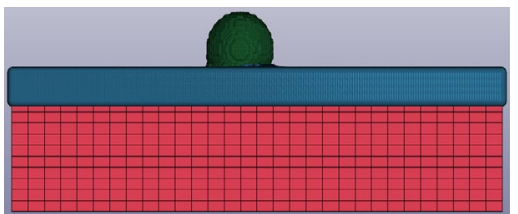

(f)

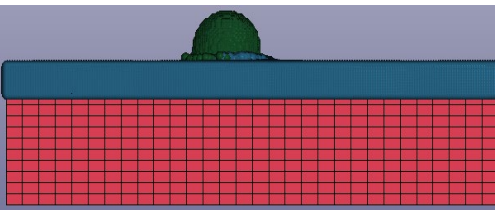

(i)

Fig.2. Side view of the impact with different velocities and impact angles (a) $100 \mathrm{~m} / \mathrm{s} \& 0^{\circ}$, (b) $100 \mathrm{~m} / \mathrm{s} \& 30^{\circ}$, (c) $100 \mathrm{~m} / \mathrm{s} \& 60^{\circ}$, (d) $200 \mathrm{~m} / \mathrm{s} \& 0^{\circ}$, (e) $200 \mathrm{~m} / \mathrm{s} \& 30^{\circ}$, (f) $200 \mathrm{~m} / \mathrm{s} \& 60^{\circ},(\mathrm{g})$ $300 \mathrm{~m} / \mathrm{s} \& 0^{\circ}$, (h) $300 \mathrm{~m} / \mathrm{s} \& 30^{\circ}$, and (i) $300 \mathrm{~m} / \mathrm{s} \& 60^{\circ}$ 

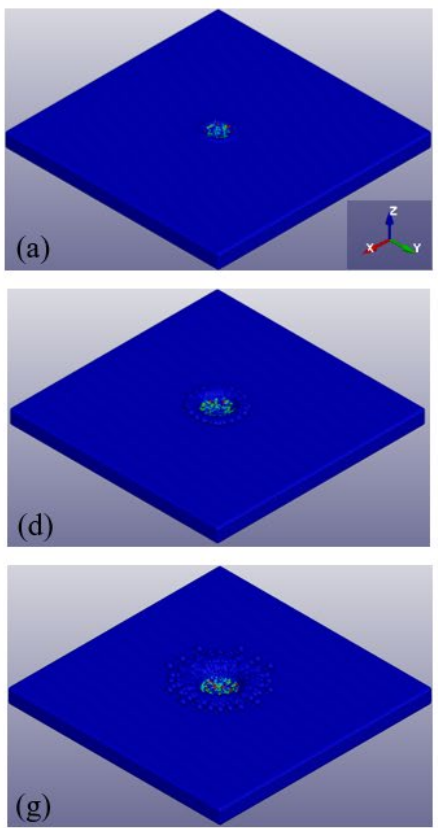
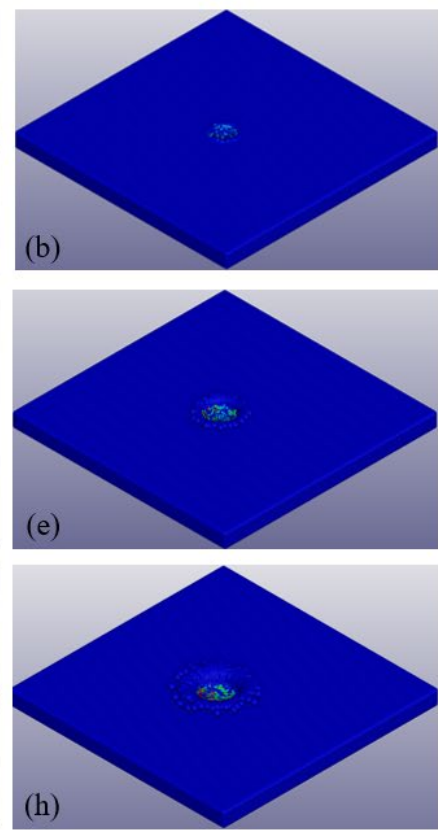
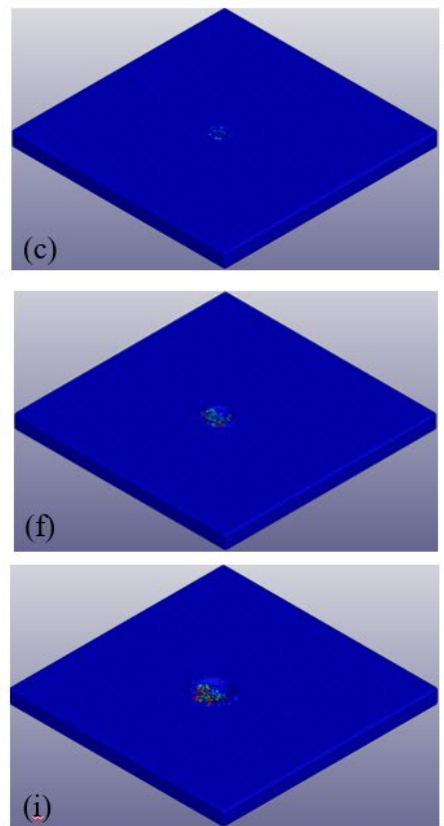

von Mises stress (GPa)

1.2e-07

1.1e-07

9.5e-08

8.3e-08

7.2e-08

$6.0 \mathrm{e}-08$

4.8e-08

$3.6 \mathrm{e}-08$

$2.4 \mathrm{e}-08$

$1.2 \mathrm{e}-08$

$0.0 \mathrm{e}+00$

Fig.3. von Mises stress distributions in the coating layers at the end of impact: (a) $100 \mathrm{~m} / \mathrm{s} \& 0^{\circ}$,

(b) $100 \mathrm{~m} / \mathrm{s} \& 30^{\circ}$, (c) $100 \mathrm{~m} / \mathrm{s} \& 60^{\circ}$, (d) $200 \mathrm{~m} / \mathrm{s} \& 0^{\circ}$, (e) $200 \mathrm{~m} / \mathrm{s} \& 30^{\circ}$, (f) $200 \mathrm{~m} / \mathrm{s} \& 60^{\circ}$,

(g) $300 \mathrm{~m} / \mathrm{s} \& 0^{\circ}$, (h) $300 \mathrm{~m} / \mathrm{s} \& 30^{\circ}$, and (i) $300 \mathrm{~m} / \mathrm{s} \& 60^{\circ}$ 


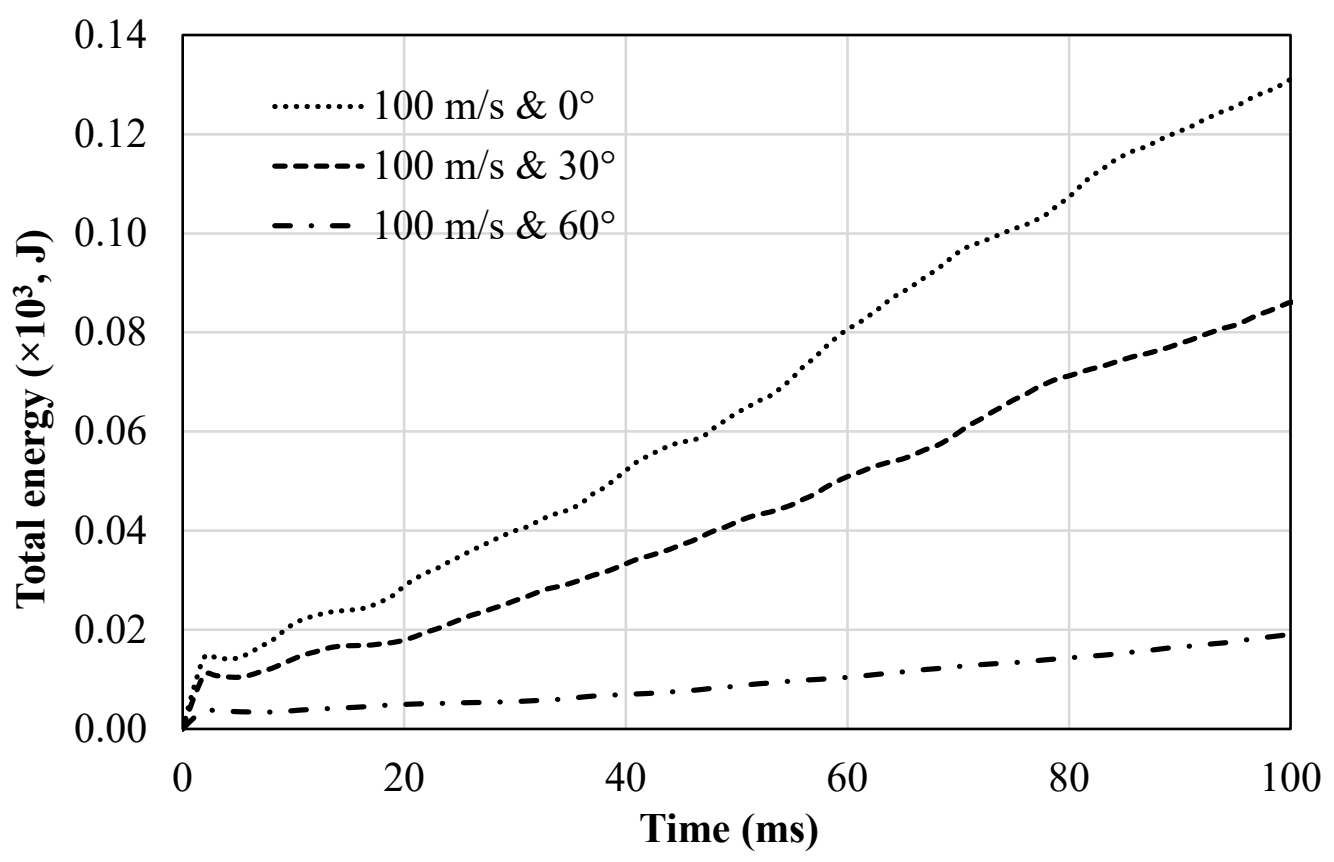

(a)

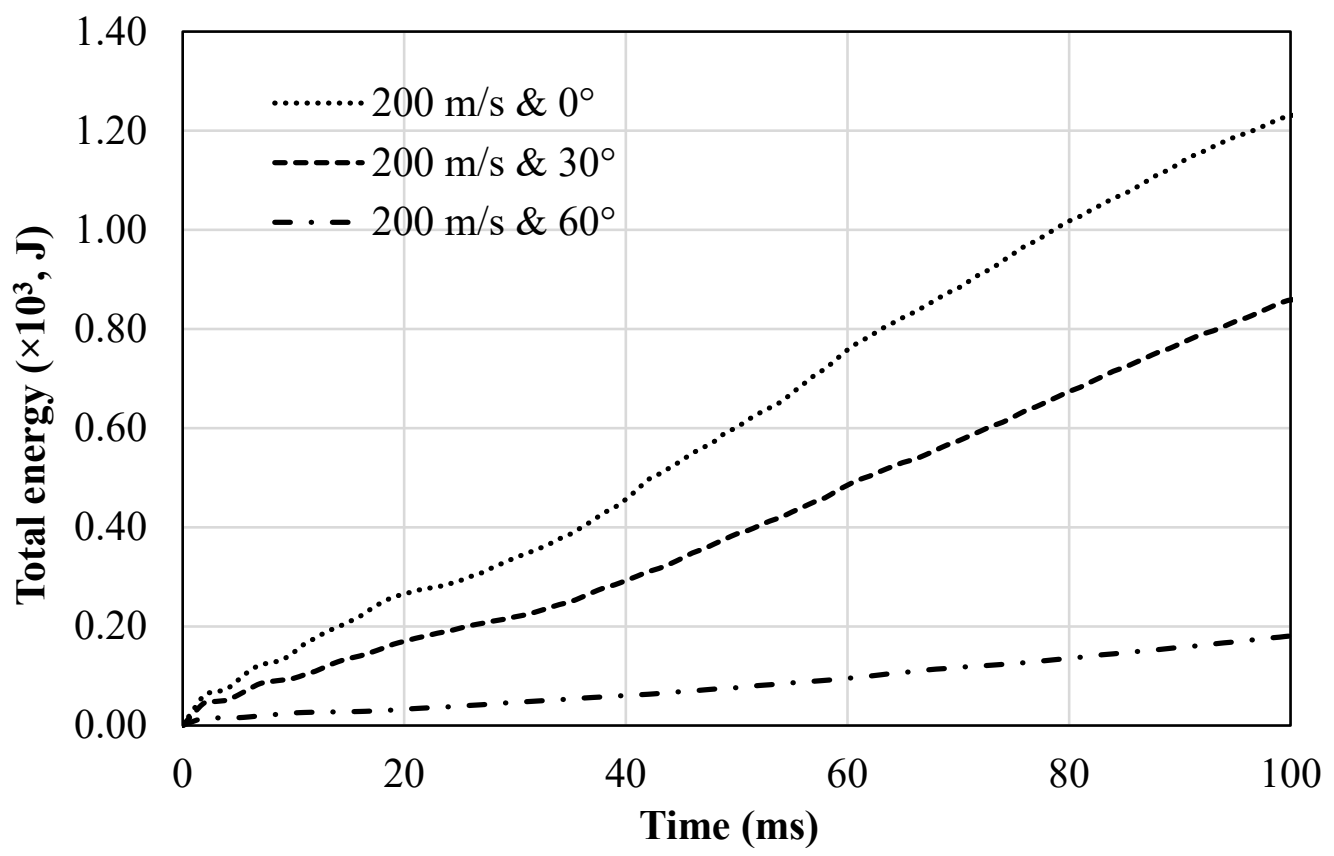

MATS-19-1214, Zhang, Page 29 
(b)

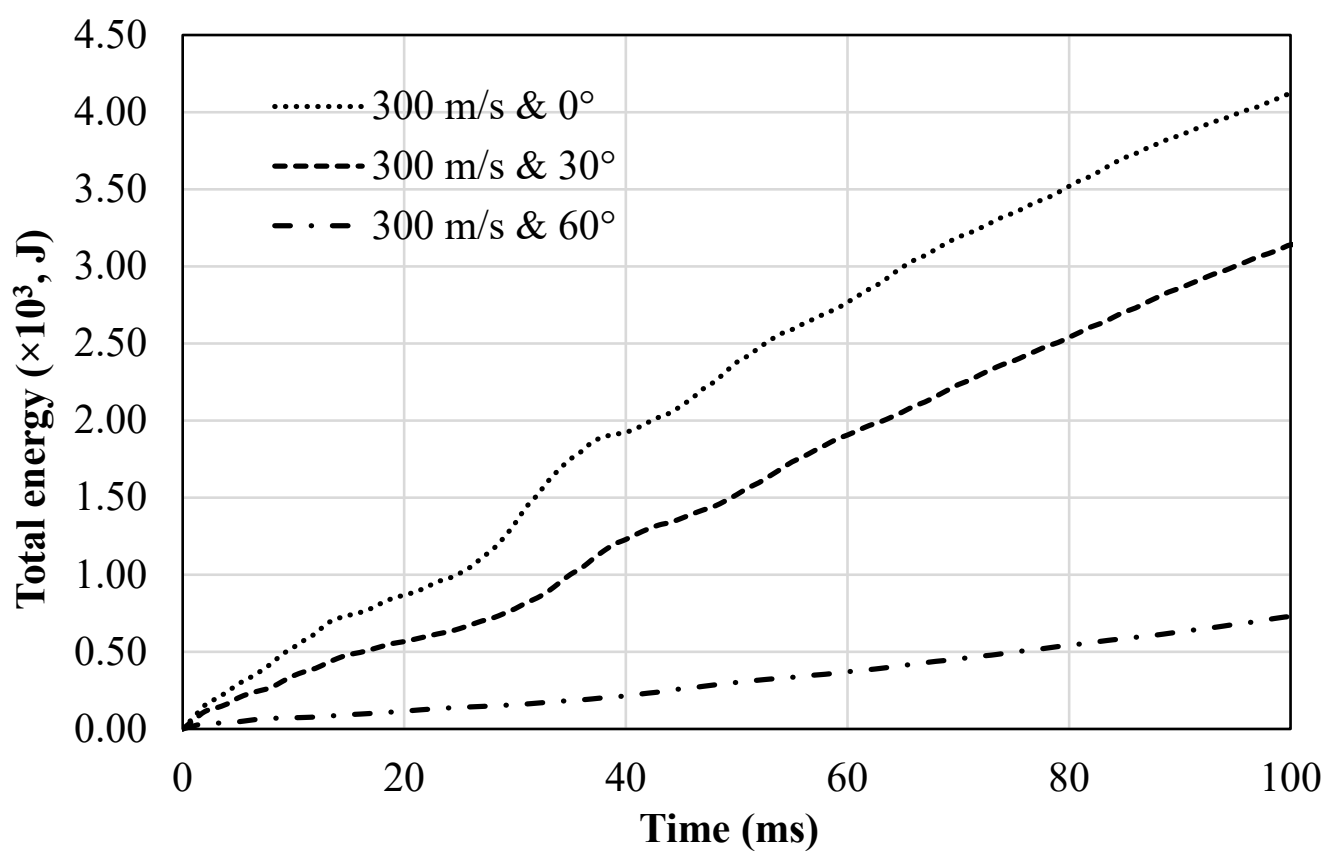

(c)

Fig.4. Total energy evolutions of the coating layer at different impact angles and velocities. (a) $100 \mathrm{~m} / \mathrm{s} \& 0^{\circ}, 30^{\circ}, 60^{\circ}$; (b) $200 \mathrm{~m} / \mathrm{s} \& 0^{\circ}, 30^{\circ}, 60^{\circ}$; (c) $300 \mathrm{~m} / \mathrm{s} \& 0^{\circ}, 30^{\circ}, 60^{\circ}$. 


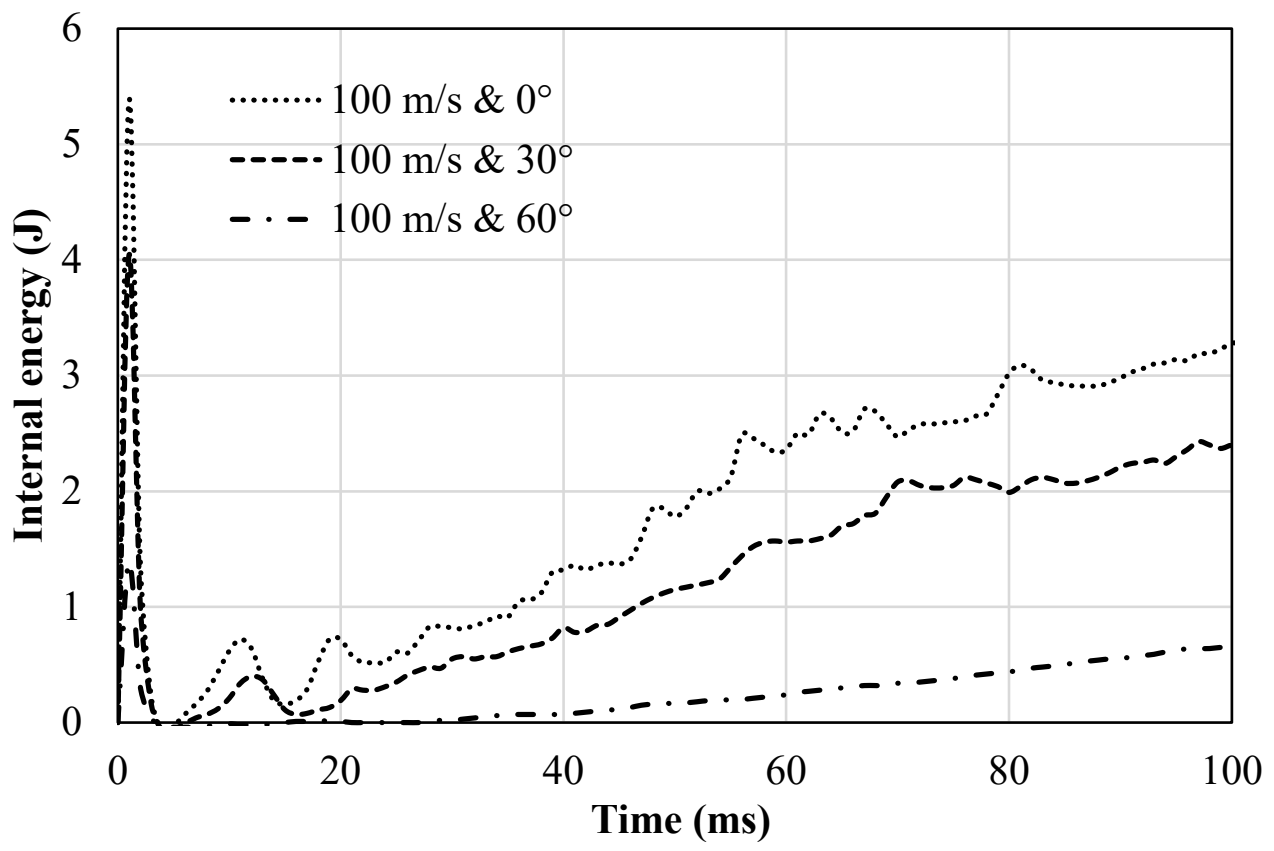

(a) 


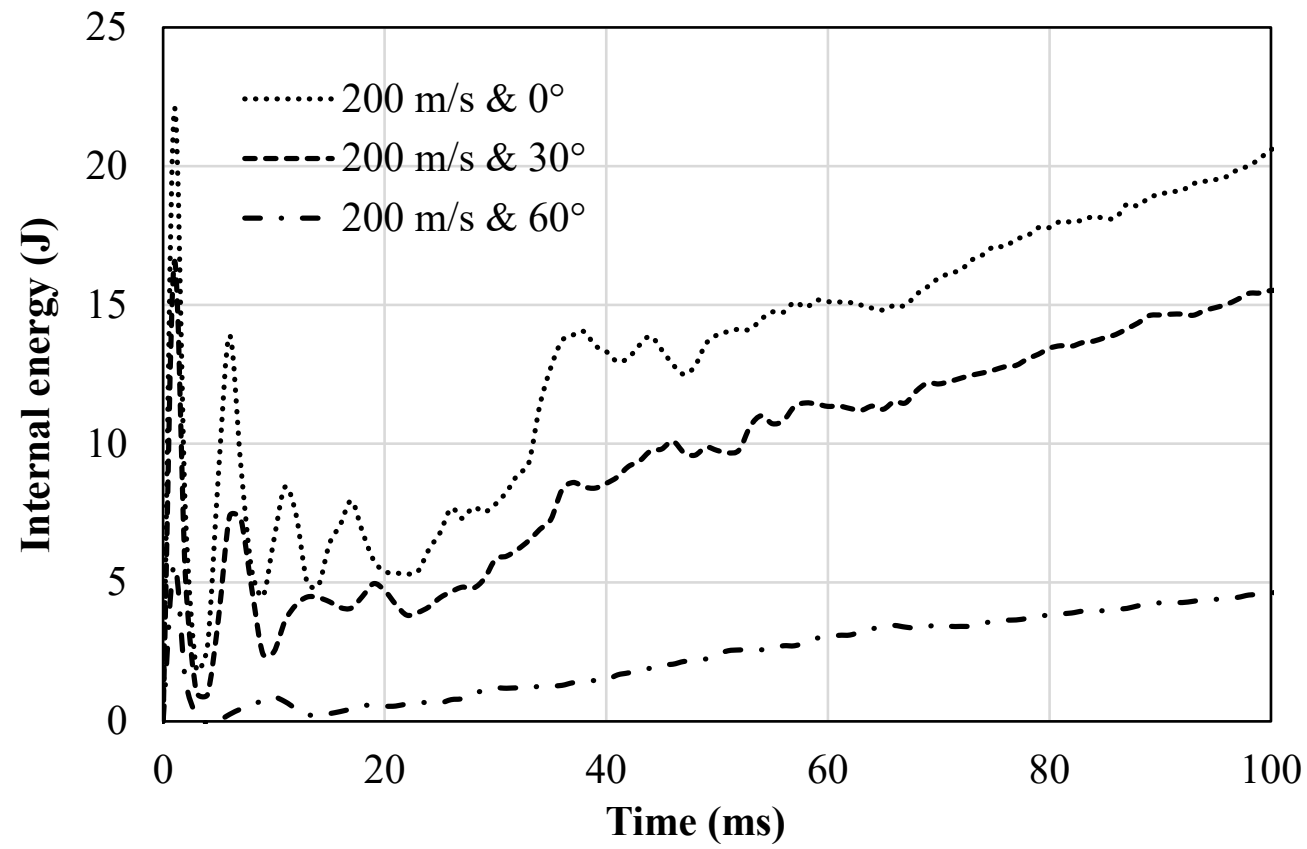

(b)

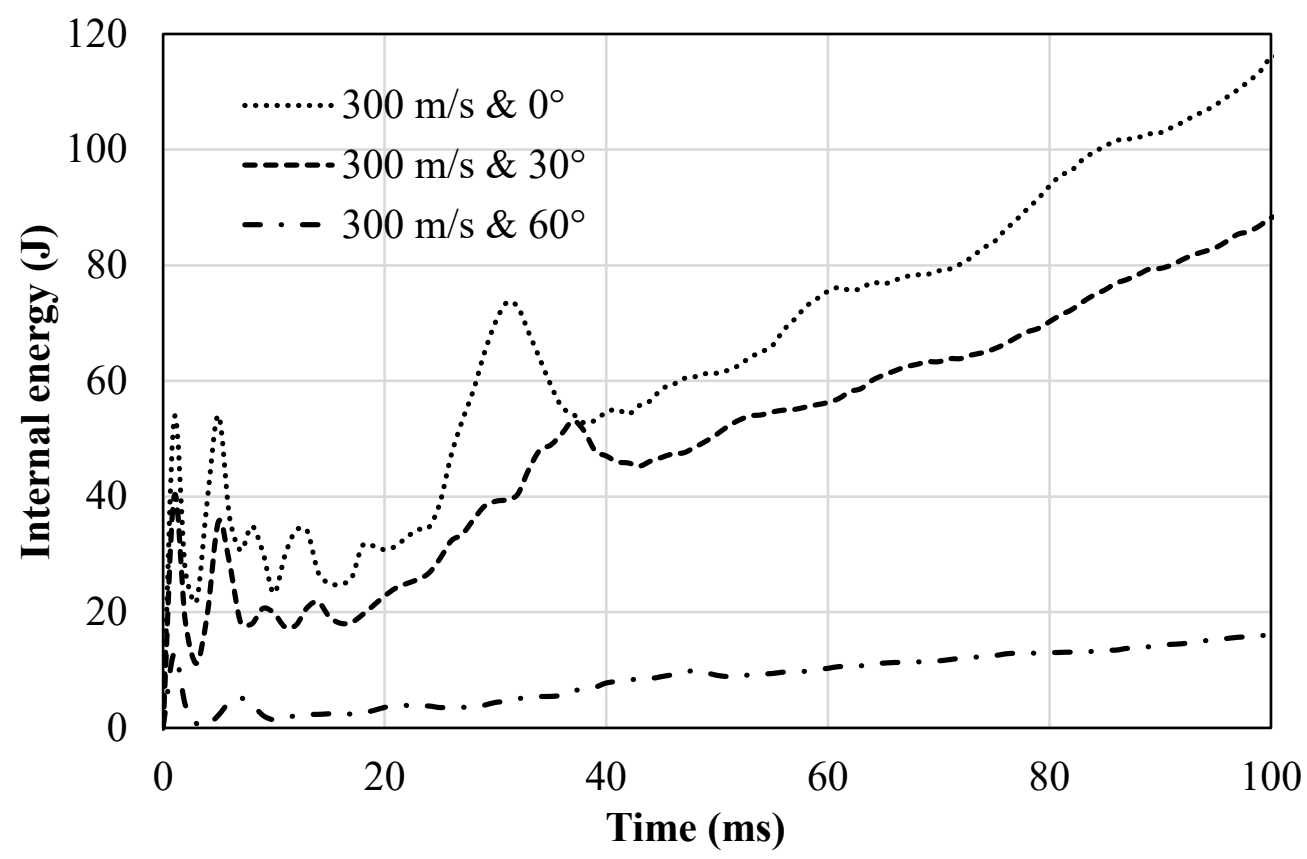

(c) 
Fig.5. Internal energy evolution of the coating layer at different impact angles and velocities. (a) $100 \mathrm{~m} / \mathrm{s} \& 0^{\circ}, 30^{\circ}, 60^{\circ}$; (b) $200 \mathrm{~m} / \mathrm{s} \& 0^{\circ}, 30^{\circ}, 60^{\circ}$; (c) $300 \mathrm{~m} / \mathrm{s} \& 0^{\circ}, 30^{\circ}, 60^{\circ}$. 


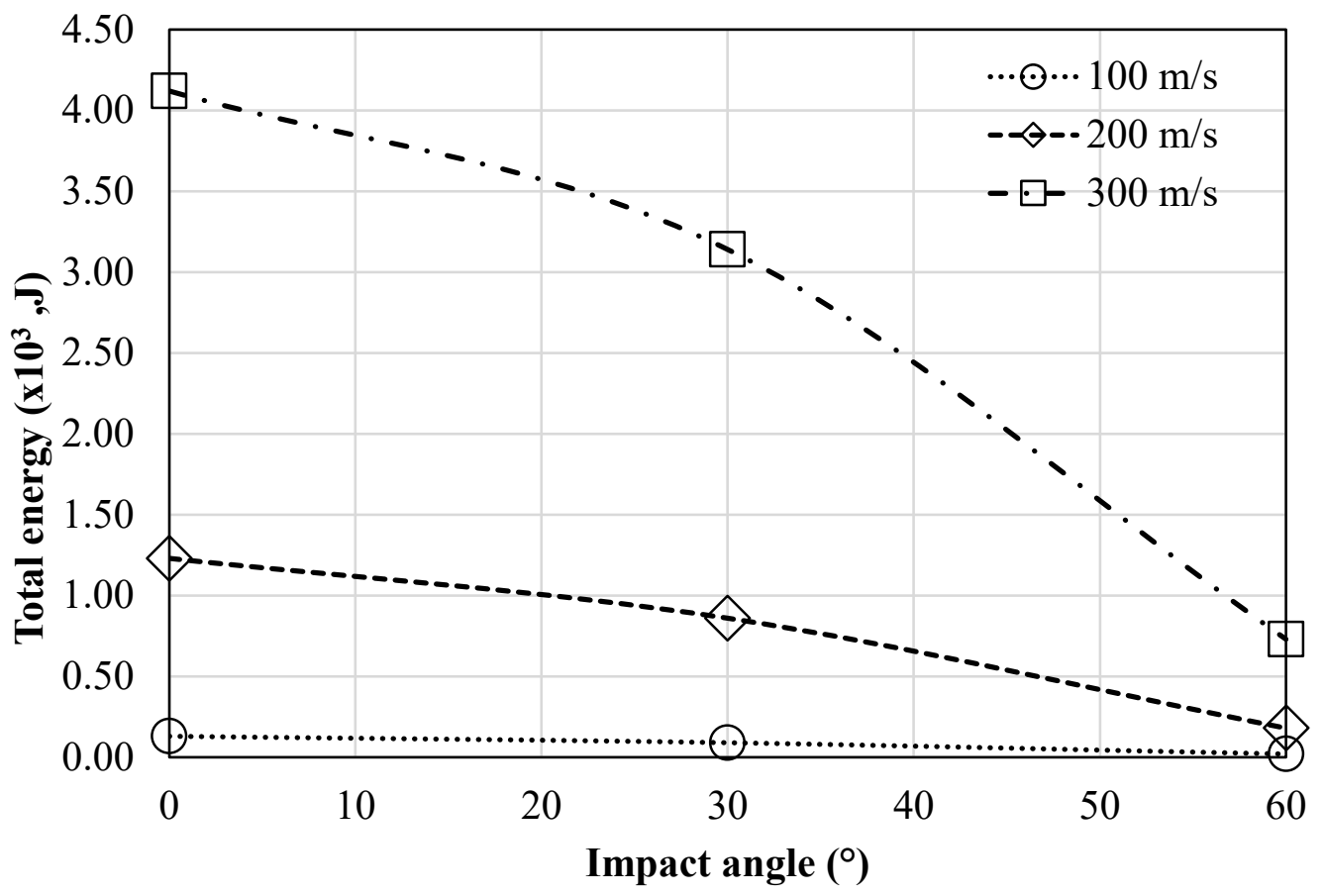

Fig.6. The final total energy values of SPH coating layer at different impact angles and velocities at the end of impact at $100 \mathrm{~ms}$. 


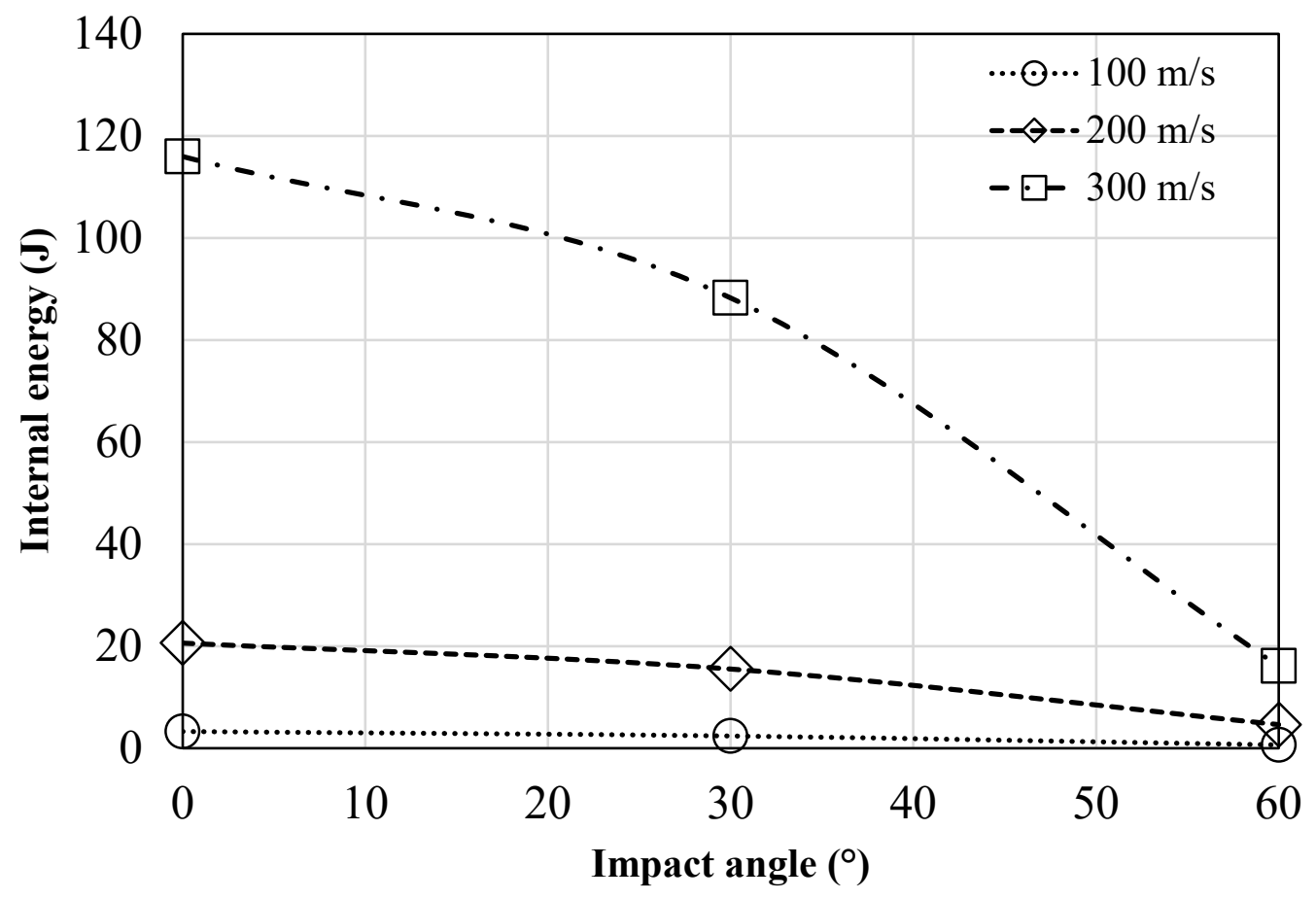

Fig.7. The final internal energy values of SPH coating layer at different impact angles and velocities at the end of impact at $100 \mathrm{~ms}$. 


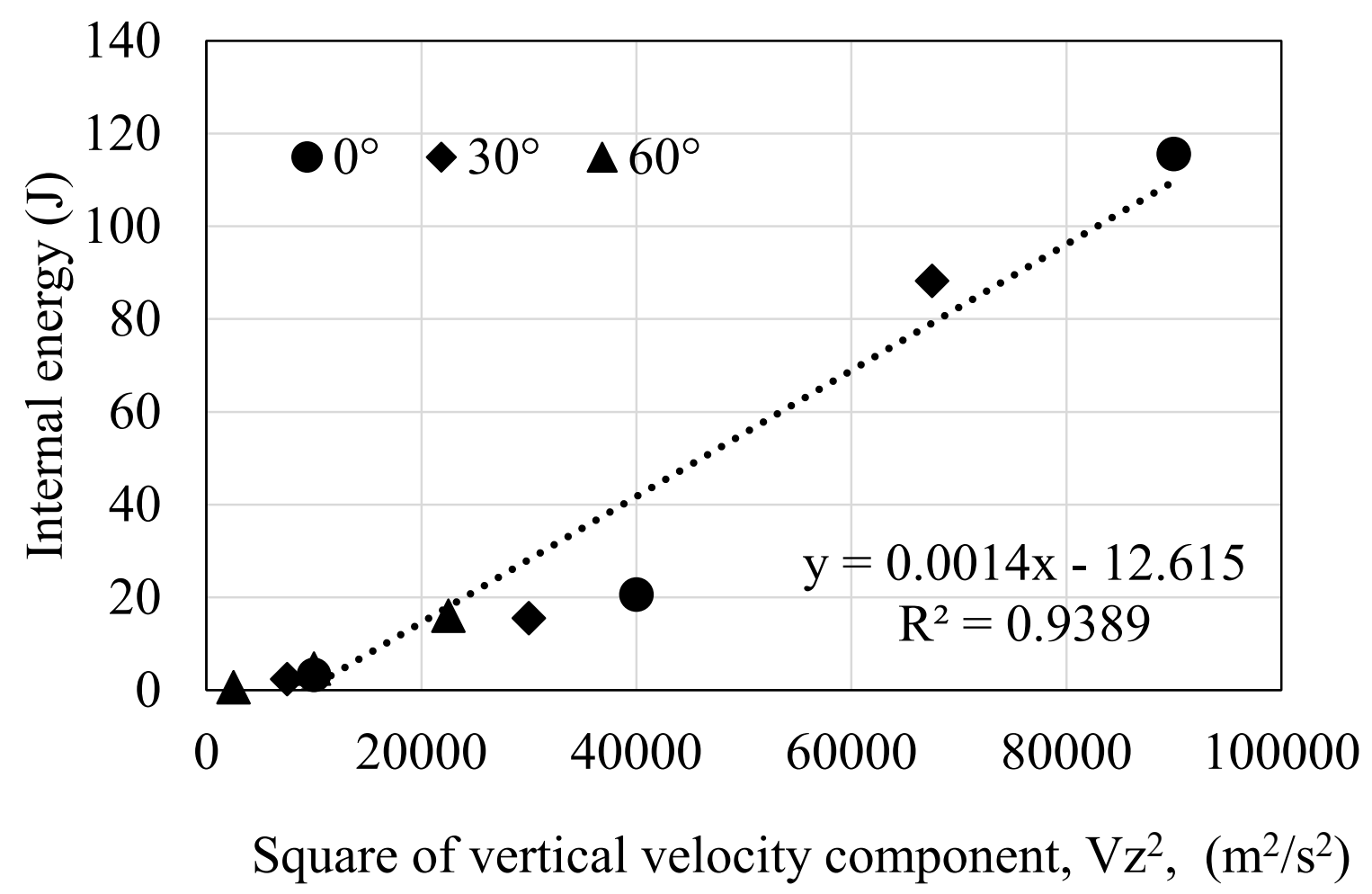

Fig. 8. Internal energy of the coating as a function of square of the vertical velocity component of the particle. 


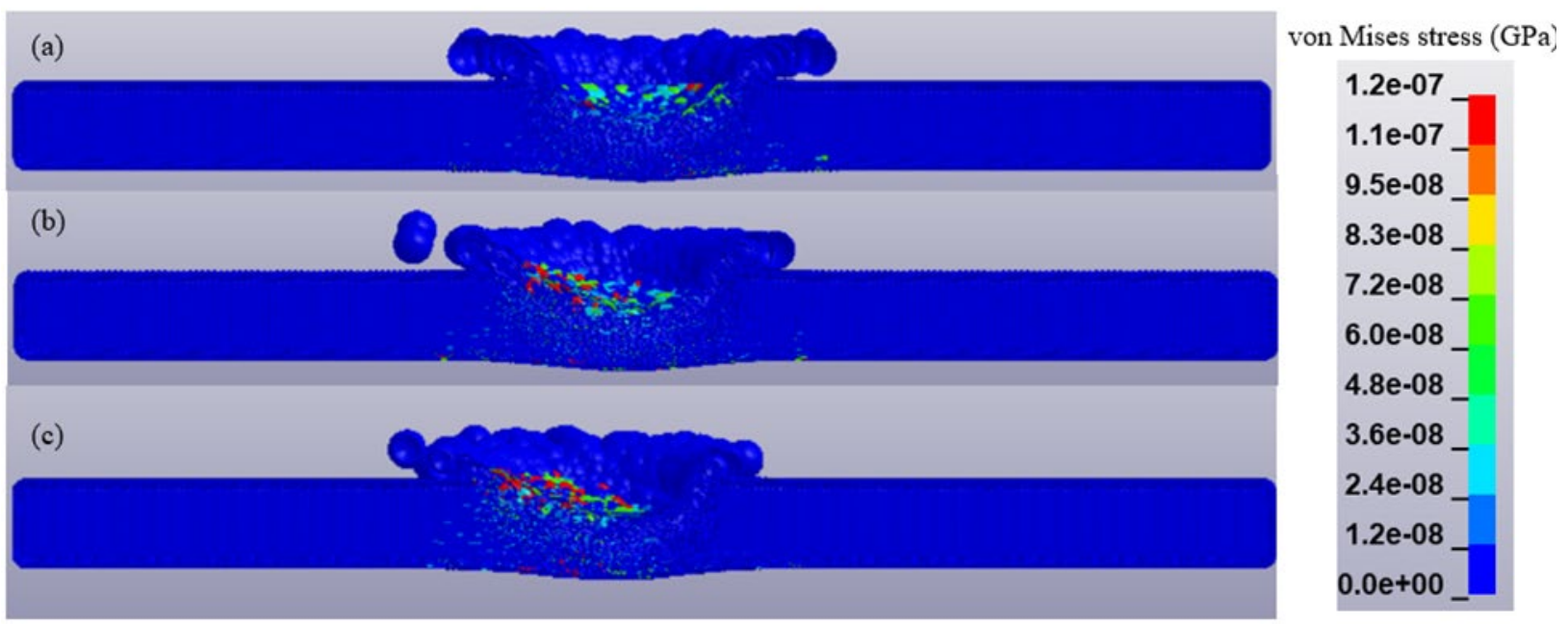

Fig.9. von Mises stress and penetration behavior of the coating layers after the impact: Vx and $\mathrm{Vz}$ are (a) $\mathrm{Vx}=0 \mathrm{~m} / \mathrm{s} \& 259.8 \mathrm{~m} / \mathrm{s}$, (b) $150 \mathrm{~m} / \mathrm{s} \& 259.8 \mathrm{~m} / \mathrm{s}$, and (c) $259.8 \mathrm{~m} / \mathrm{s} \& 259.8 \mathrm{~m} / \mathrm{s}$. 


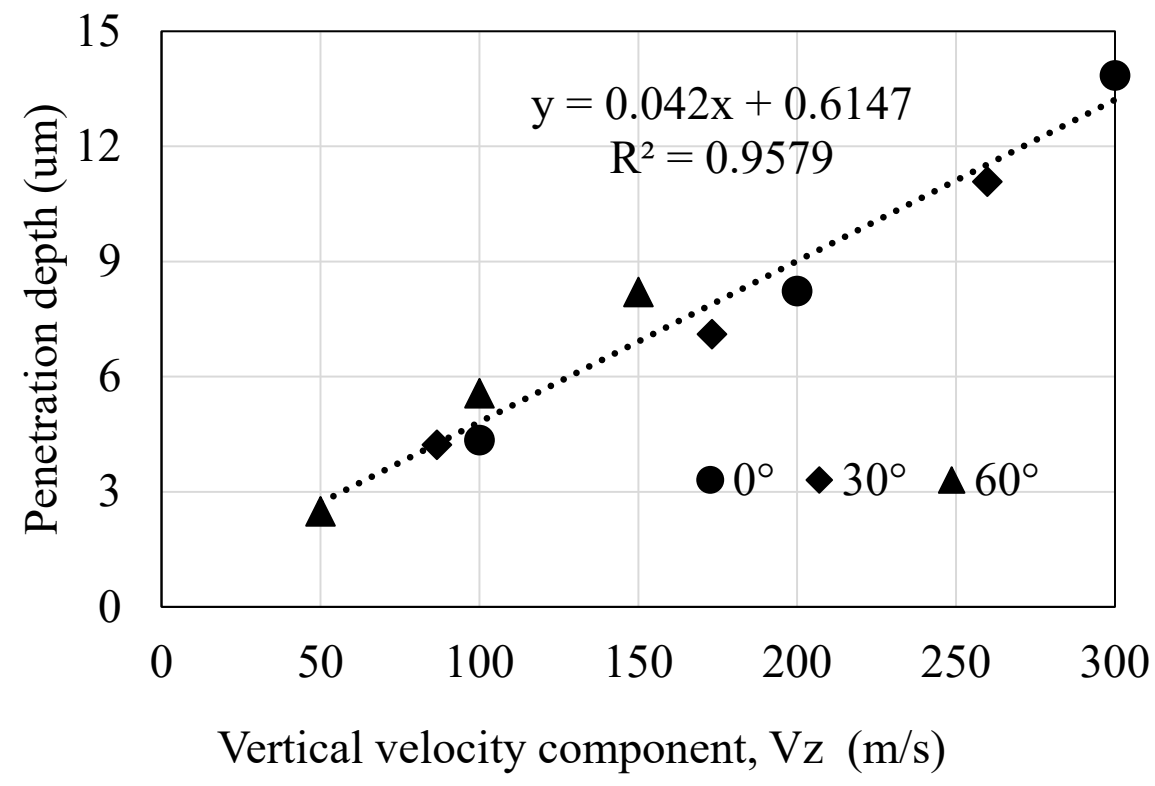

Fig.10. Coating penetration depth as a function of particle's vertical velocity component 


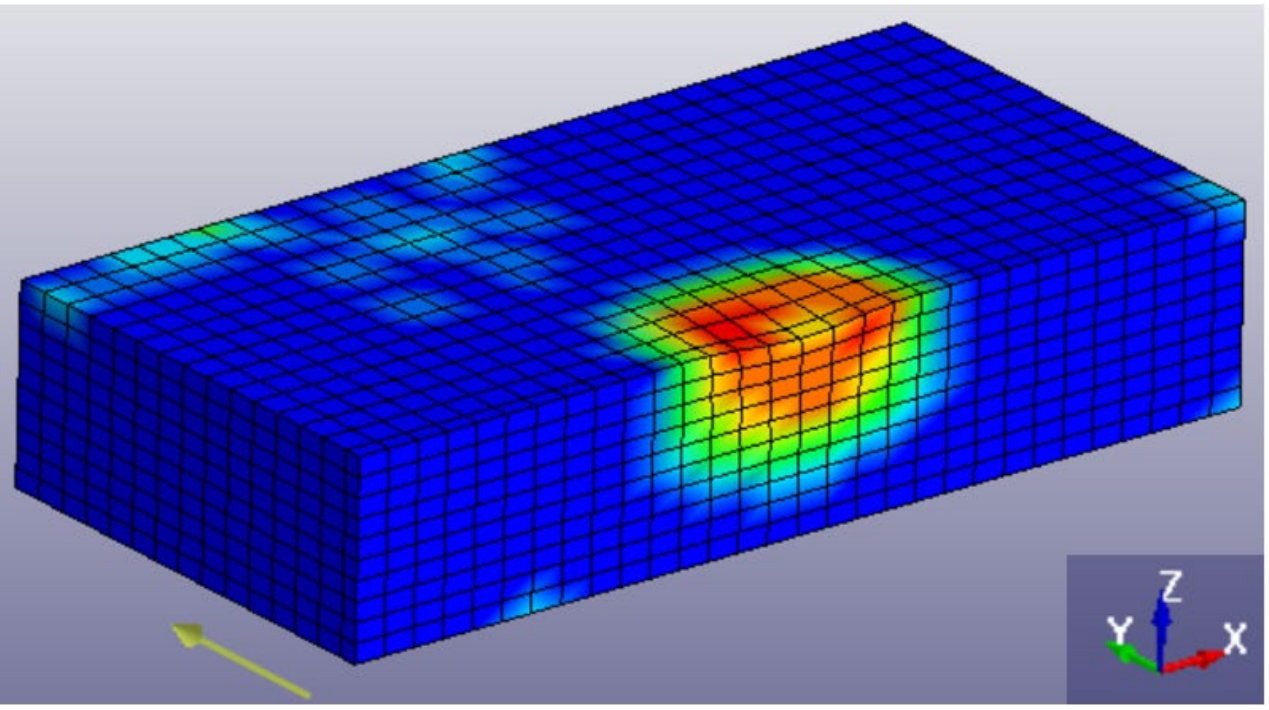

von Mises stress (GPa)

$8.1 \mathrm{e}-02$
$7.3 \mathrm{e}-02$
$6.5 \mathrm{e}-02$
$5.7 \mathrm{e}-02$
$4.9 \mathrm{e}-02$
$4.0 \mathrm{e}-02$
$3.2 \mathrm{e}-02$
$2.4 \mathrm{e}-02$
$1.6 \mathrm{e}-02$
$8.1 \mathrm{e}-03$
$0.0 \mathrm{e}+00$

Fig.11. von Mises stress distribution in the FEM layer of the combination $300 \mathrm{~m} / \mathrm{s} \& 0^{\circ}$ 


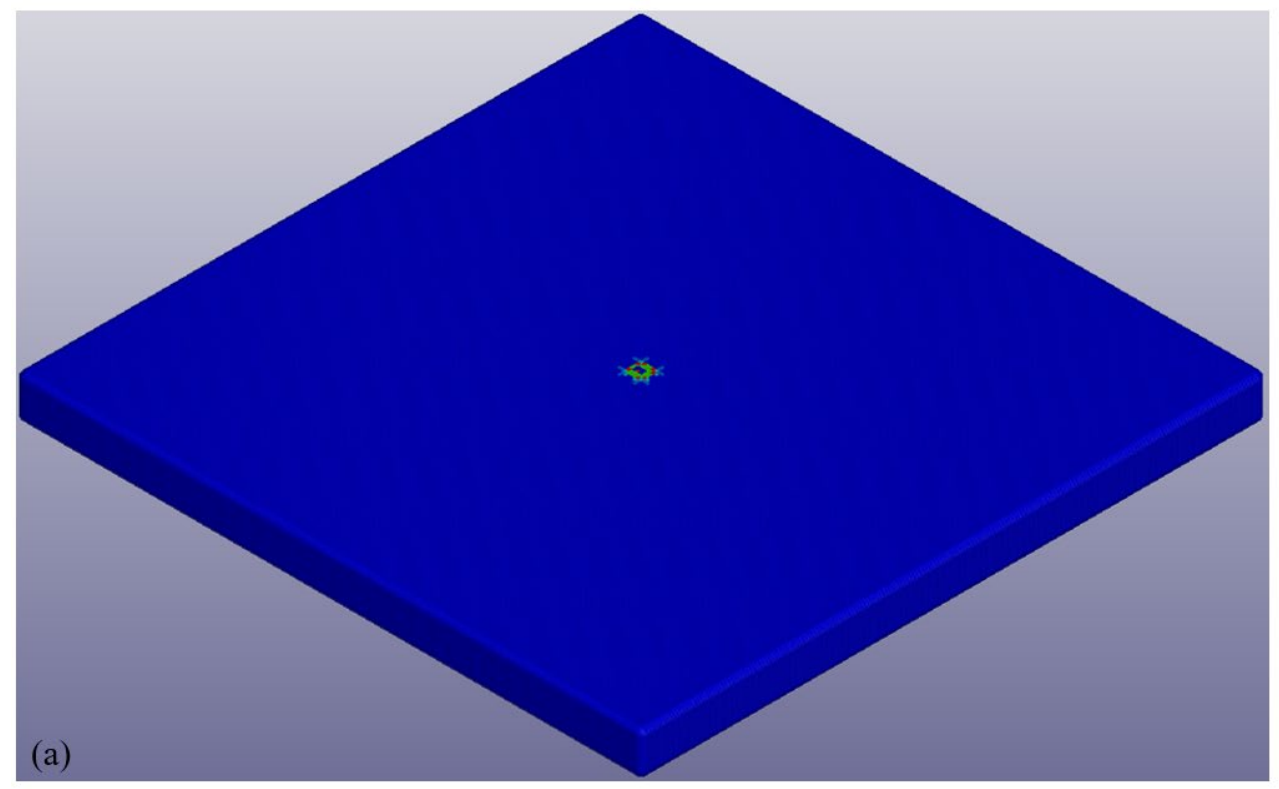

Von Mises stress (GPa)

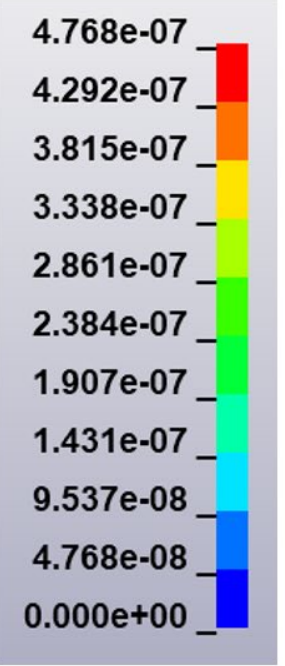

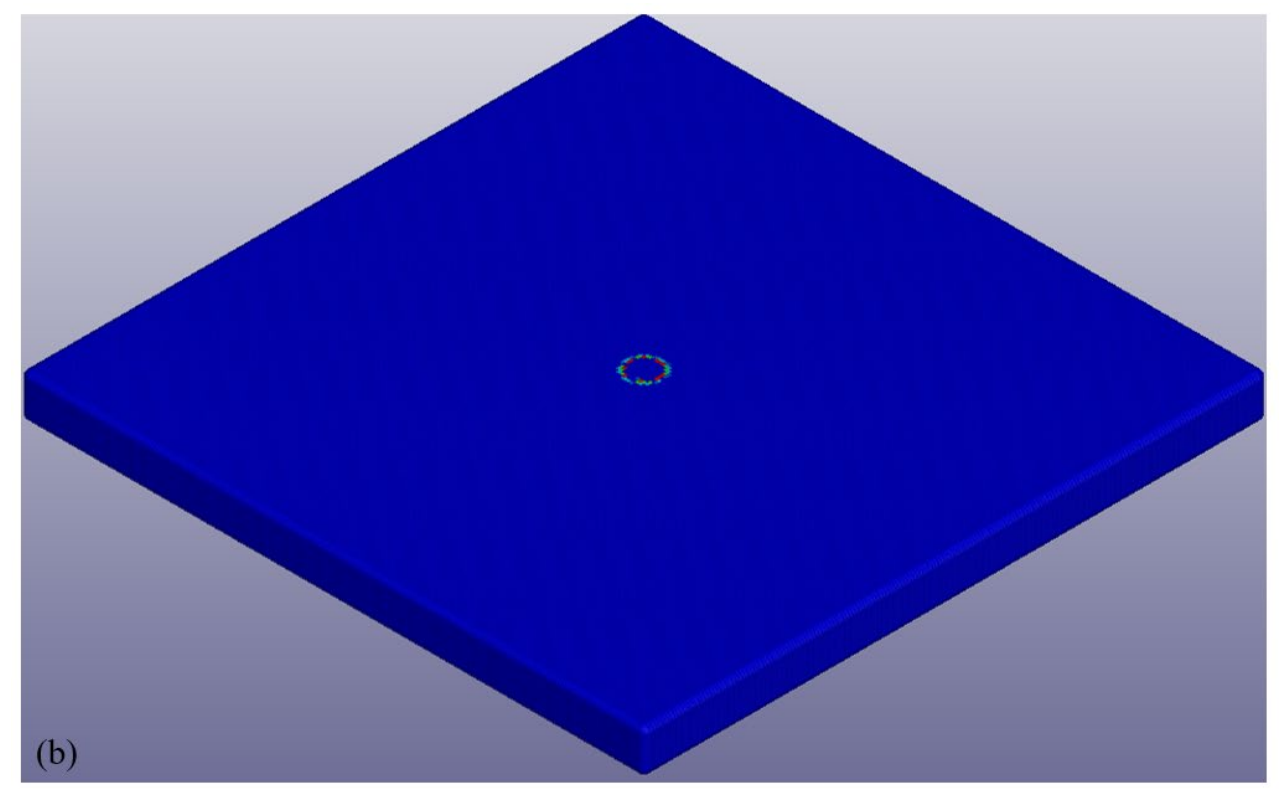

Von Mises stress (GPa)

2.980e-08

2.682e- 08

2.384e-08

2.086e-08

$1.788 \mathrm{e}-08$

$1.490 \mathrm{e}-08$

1.192e-08

8.941e-09

5.960e-09

2.980e-09

$0.000 \mathrm{e}+00$ 


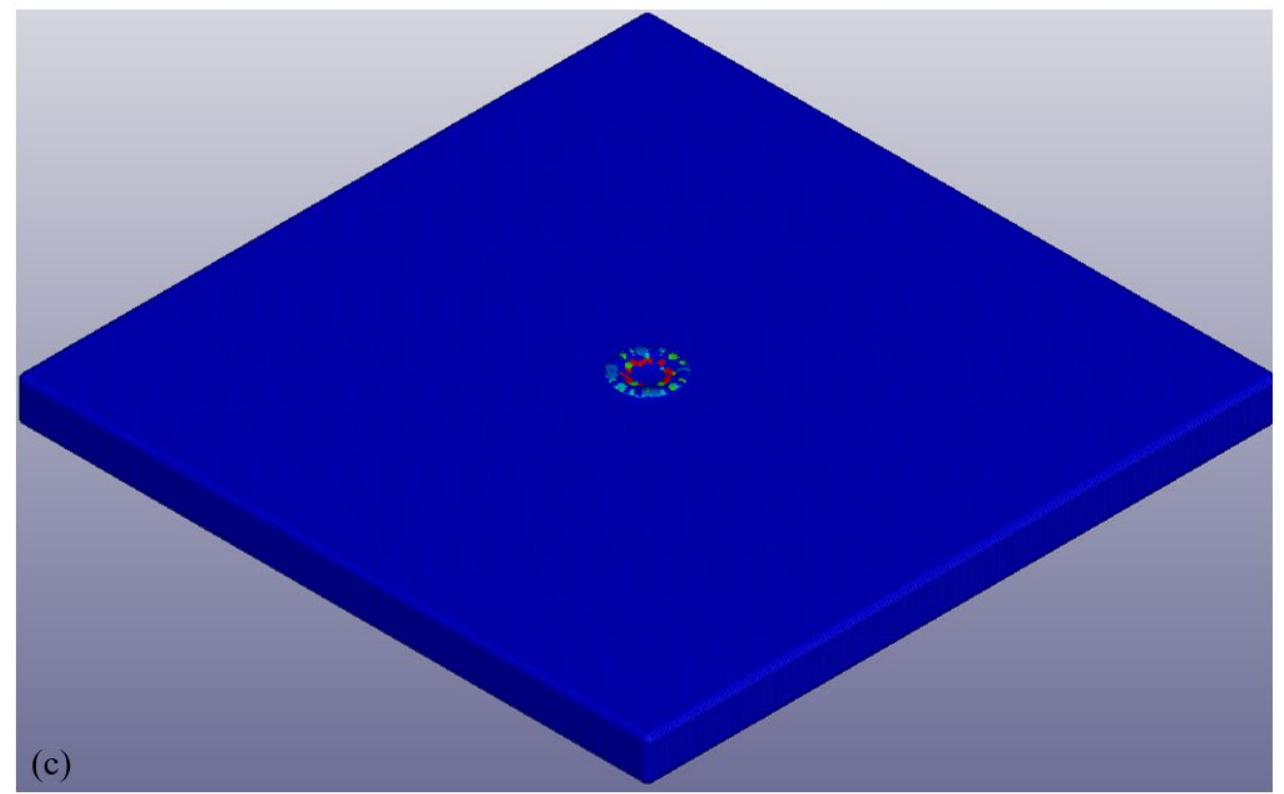

Von Mises stress $(\mathrm{GPa})$

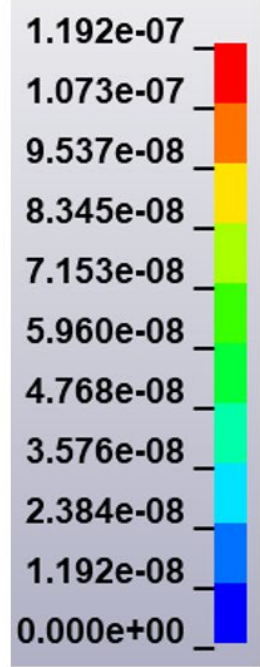

Fig.12. von Mises stress distribution evolutions of SPH coating layer at the combination $100 \mathrm{~m} / \mathrm{s}$ $\& 0^{\circ}$ at different times. (a) $1 \mathrm{~ms}$; (b) $4 \mathrm{~ms}$; and (c) $50 \mathrm{~ms}$. 

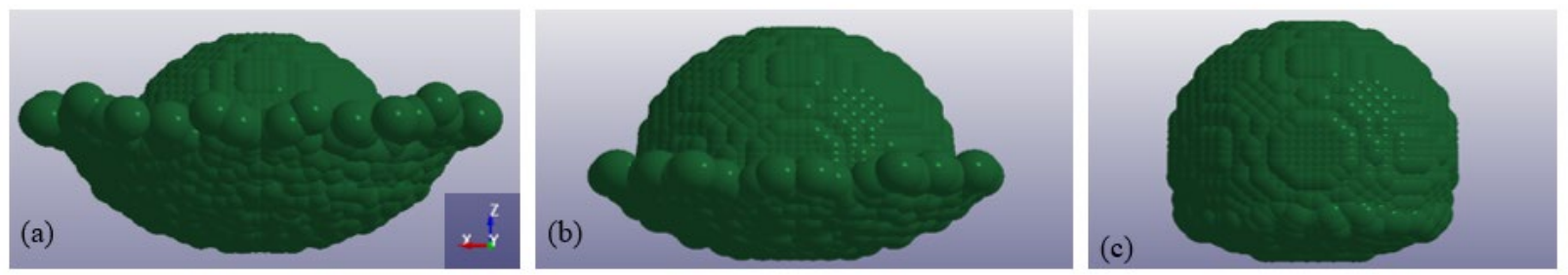

Fig.13. The spherical particle deformation after the impact: (a) $300 \mathrm{~m} / \mathrm{s} \& 0^{\circ}$, (b) $200 \mathrm{~m} / \mathrm{s} \& 0^{\circ}$, (c) $100 \mathrm{~m} / \mathrm{s} \& 0^{\circ}$. 

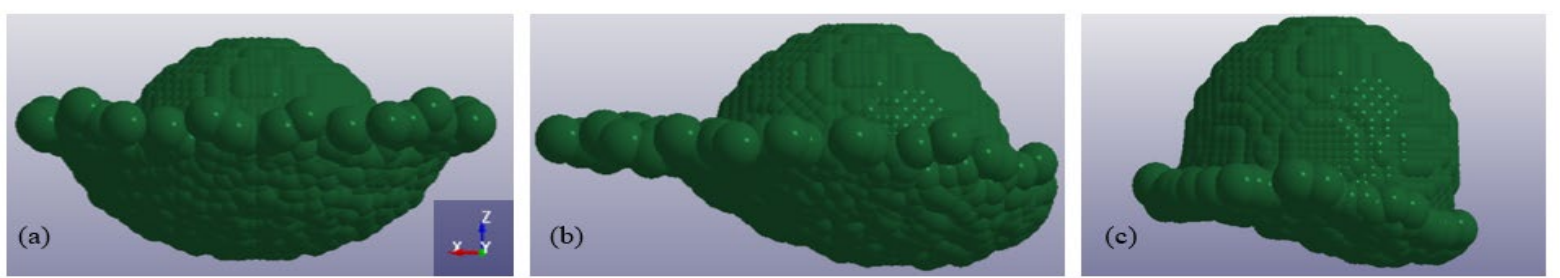

Fig.14. The spherical particle deformation after the impact: (a) $300 \mathrm{~m} / \mathrm{s} \& 0^{\circ}$, (b) $300 \mathrm{~m} / \mathrm{s} \& 30^{\circ}$, (c) $300 \mathrm{~m} / \mathrm{s} \& 60^{\circ}$. 


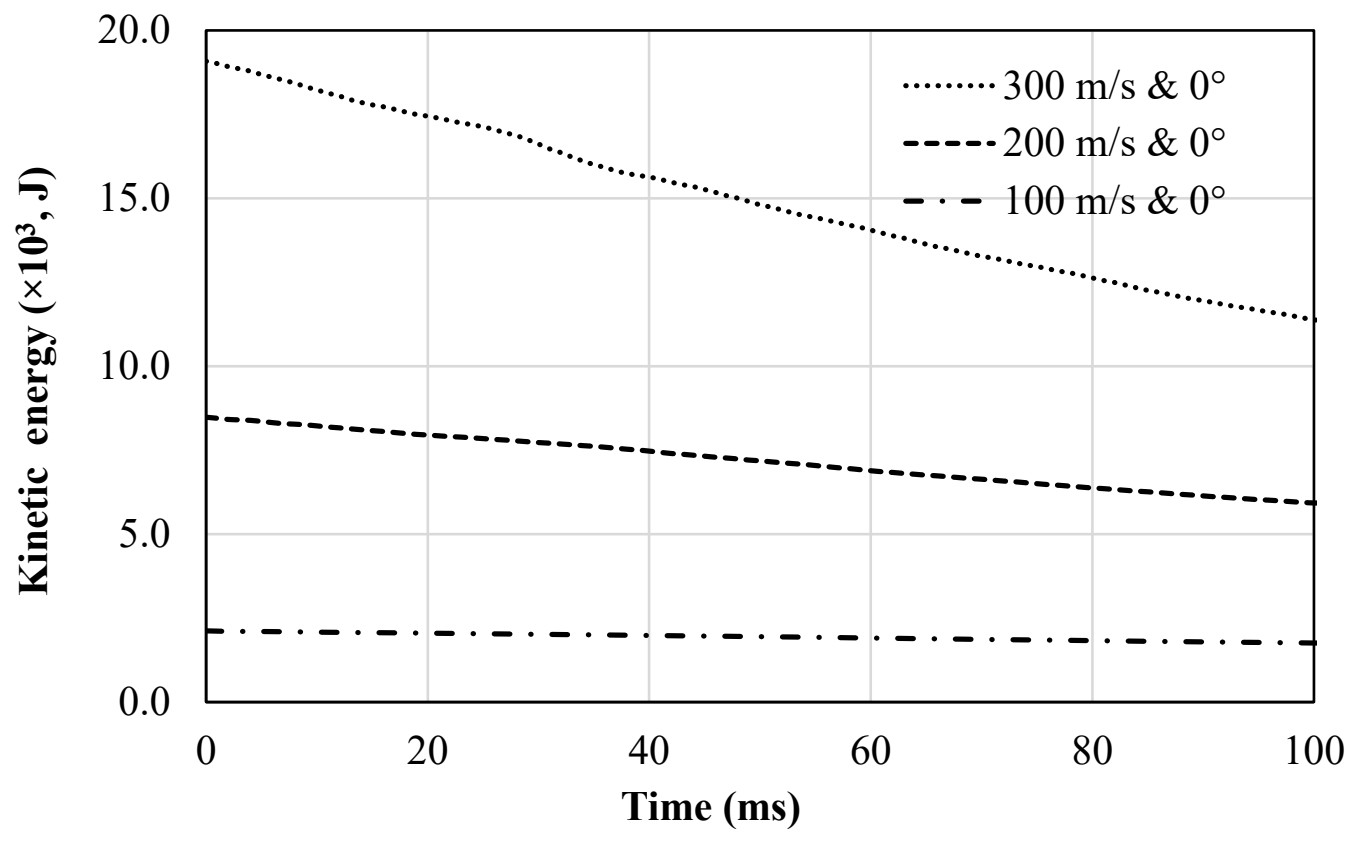

Fig.15. Kinetic energy evolutions of spherical particle at different impact velocities 


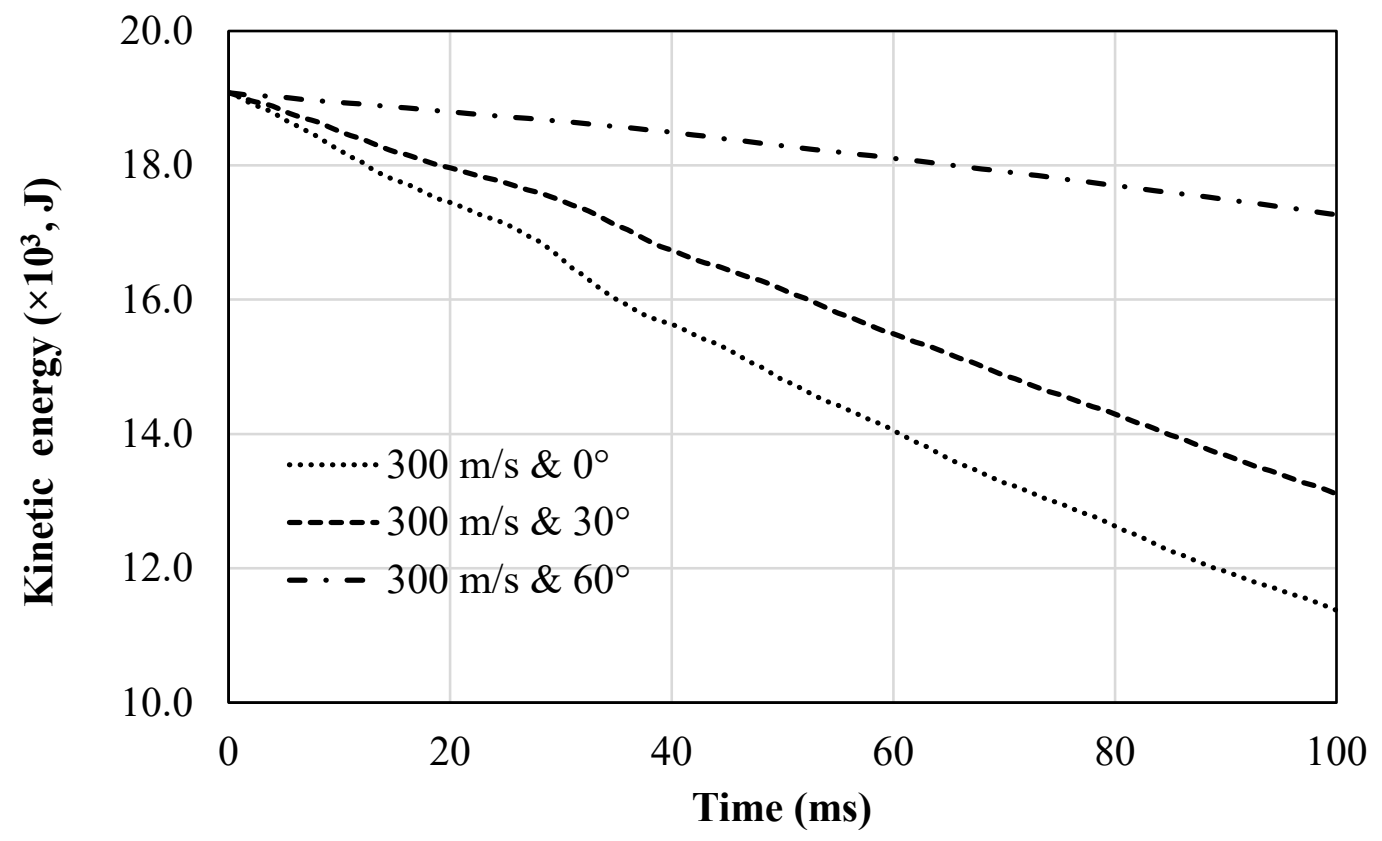

Fig.16. Kinetic energy evolution of spherical particle at different impact angles 


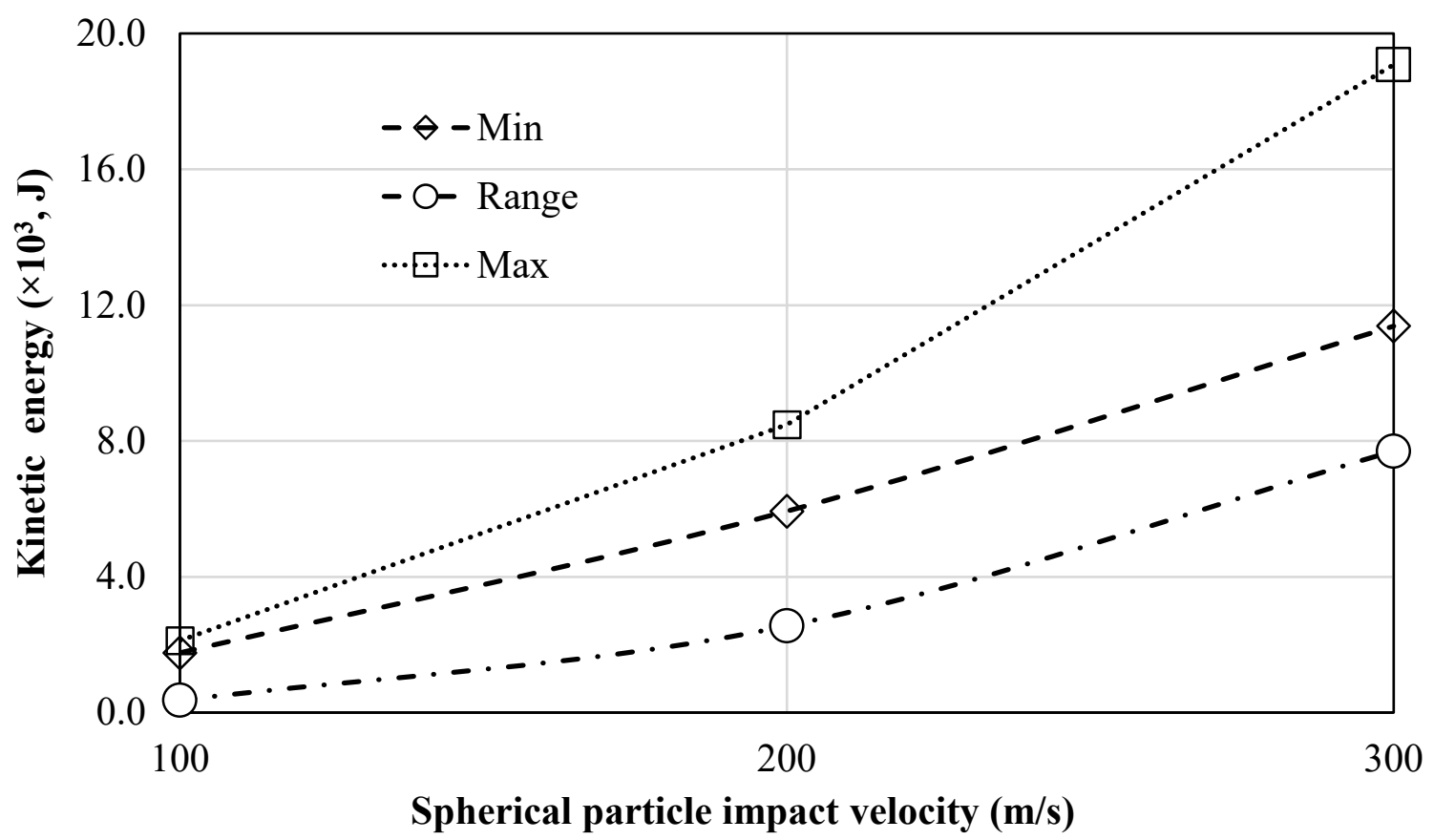

Fig. 17. The spherical particle's maximum, minimum and range of kinetic energy values at different impact velocities: $300 \mathrm{~m} / \mathrm{s} \& 0^{\circ}, 200 \mathrm{~m} / \mathrm{s} \& 0^{\circ}$ and $100 \mathrm{~m} / \mathrm{s} \& 0^{\circ}$. 


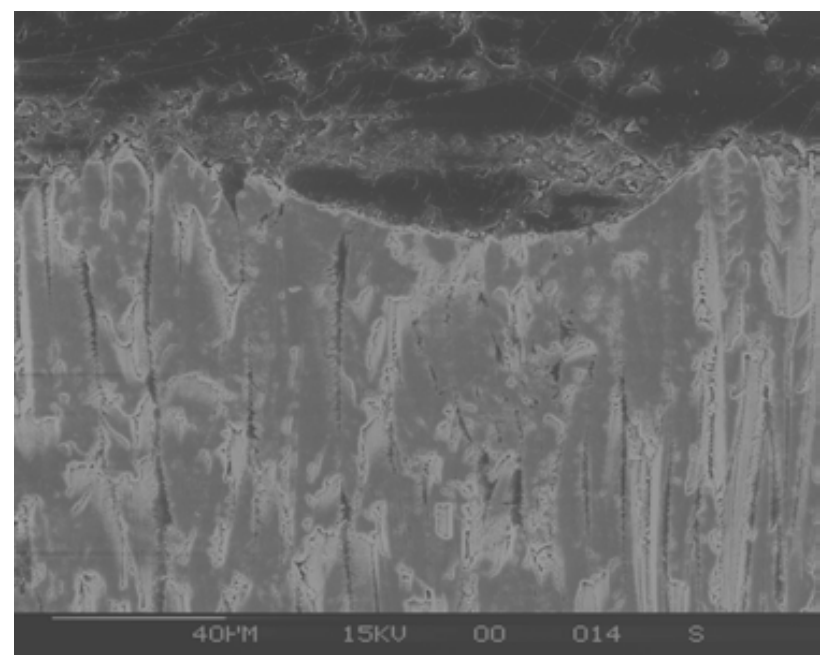

Fig.18. Cross sectional view of the experimental impact pit of YSZ ceramic coating [25]. 